\title{
Cryptic speciation and genetic structure of widely distributed brittle stars (Ophiuroidea) in Europe
}

\author{
Rocío Pérez-Portela, Vitor Almada \& Xavier Turon
}

Submitted: 21 March 2012

Accepted: 15 September 2012

doi:10.1111/j.1463-6409.2012.00573.x
Pérez-Portela, R., Almada, V. \& Turon, X. (2012). Cryptic speciation and genetic structure of widely distributed brittle stars (Ophiuroidea) in Europe. -Zoologica Scripta, 42, 151-169.

The development of molecular techniques has led to the detection of numerous cases of cryptic speciation within widely distributed marine invertebrate species and important taxonomic revisions in all the major marine taxa. In this study, we analysed a controversial marine species complex in the genus Ophiothrix, a widespread taxon in European waters traditionally assigned to two nominal species, Ophiotbrix fragilis and O. quinquemaculata. These species are important components of the rocky shores and deep marine benthos along the North Atlantic and Mediterranean littoral. Their status (including variants of both species) has remained contentious due to overlapping variability in morphological characters. In this study, we analysed the genetic and morphological differences of Ophiothrix lineages along the Atlantic and Mediterranean coasts. We also assessed population genetic structure in the Atlantic and Mediterranean basins by sequencing two mitochondrial genes, the 16S rRNA gene and COI gene, of 221 specimens from 13 locations. Phylogenetic analyses demonstrated the existence of two genetically distinct lineages, attributable to two different species although unrelated to previous taxonomic distinctions. Morphological differences could also be detected between these lineages. Samples from the Northeast Atlantic and one from the deep Mediterranean grouped within Lineage I, whereas Lineage II pooled together the southern Atlantic and rocky shallow Mediterranean samples. In the northern region of the Iberian Peninsula and at a deep locality in the Mediterranean, both lineages overlap. Speciation processes likely happened during the Mio-Pliocene transition (about 4.8-7.5 million years ago), when marine-level oscillations led to the blockage of major marine corridors in Europe and promoted genetic isolation by vicariance. Secondary contact between lineages following sea-level increases and recolonization during the refilling of the Mediterranean after the Miocene salinity crisis could explain the present-day distribution of genetic variability. No barriers to gene flow along the Atlanto-Mediterranean area were detected for Lineage II, and the lack of genetic structure could be caused by a mixture of several factors, such as wide dispersal potential, recent demographic expansion and large population size.

Corresponding author: Rocío Pérez-Portela, Department of Animal Biology (Invertebrates), Faculty of Biology, University of Barcelona, 645, Diagonal Avenue, 08028 Barcelona, Spain and Center for Advanced Studies of Blanes (CEAB-CSIC), Accés a la Cala St. Francesc 14, Blanes, Girona E-17300, Spain. E-mail: perezportela@ceab.csic.es

Vitor Almada, Eco-Ethology Research Unit, Instituto Superior de Psicologia Aplicada (ISPA), Rua Fardim do Tabaco, 34, 1149-041 Lisbon, Portugal. E-mail: valmada@netcabo.pt

Xavier Turon, Center for Advanced Studies of Blanes (CEAB-CSIC), Accés a la Cala St. Francesc 14, Blanes, Girona E-17300, Spain. E-mail:xturon@ceab.csic.es

\section{Introduction}

Sibling species are commonly found in marine habitats (Knowlton 1993). The development of molecular techniques, primarily DNA sequencing, has given biologists a new tool for detecting numerous cases of crypticism within widely distributed taxonomic units, overturning traditional notions about biodiversity and ecological interactions. In particular, marine habitats are fertile grounds for cryptic speciation (Feral 2002; Bickford et al. 2007), and the overwhelming message from molecular tools is that 
biodiversity at the species level has been underestimated in many marine invertebrate groups (Knowlton 2000; Bucklin et al. 2011).

Phenotypic plasticity of marine invertebrates, as a response to both genetic characteristics and local environmental conditions, has complicated the discrimination of closely related taxa by traditional methods of morphological analysis (e.g. Monteiro et al. 1997; Sponer et al. 2001; Le Gac et al. 2004; Peijnenburg et al. 2006; Pérez-Portela \& Turon 2008), hindering the definition of species boundaries in many cases (Lee 2000). Thus, molecular data are especially useful for species identification when morphological characters are inconclusive (Hebert et al. 2003). In the case of echinoderm species, DNA sequences have provided an accurate tool for species identification and have the potential to identify all life history stages, including juveniles and larvae, which may be extremely difficult to distinguish at the species level (Kirby \& Lindley 2005; Ward et al. 2008; Hoareau \& Boissin 2010).

Molecular analyses have also been extensively applied to resolve marine biogeographic patterns, allowing generalizations about the factors directly involved in the genetic divergence of populations and speciation within the marine realm (e.g. Palumbi 1994; Knowlton 2000; Feral 2002; Schroth et al. 2002). In benthic marine species, the distribution patterns of genetic variability have revealed that major phylogeographic breaks are concordant with biogeographic boundaries. Dispersal capabilities and life history patterns are crucial determinants of the distribution of genetic diversity, differentiation and speciation in the sea. Species whose embryos, larvae or juveniles spend long periods of time in the water column are expected to display higher gene flow and, consequently, a weaker interpopulation genetic structure and divergence (Palumbi 1994). However, empirical data have demonstrated that genetic patterns of low connectivity can occur in species with long-lived, planktotrophic larvae and large dispersal potential (Benzie 1999; Launey et al. 2002; Hunter \& Halanych 2010), highlighting the complexity of the processes that shape the spatial distribution of species. Genetic diversity patterns in the marine realm depend on the interplay between life history features, physical barriers and historical and contemporary processes (Palumbi 1995; Benzie 1999; Patarnello et al. 2007).

The Atlanto-Mediterranean littoral region covers a wide range of subtropical, temperate and subarctic conditions, which has experienced an intricate geological and climatological history. Along the coast of Europe, the English Channel marks the transition between temperate and cold/boreal marine faunal assemblages (Cox \& Moore 2000), while the Gibraltar Strait and Alboran Sea represent the only connection between the Atlantic and
Mediterranean basins and one of the most important potential barriers to gene flow in the world's oceans (Tintoré et al. 1988; Borsa et al. 1997; Patarnello et al. 2007). In general, marine straits are key biogeographic breakpoints, due to strong current regimes and repeated disconnections and reconnections over geological timescales, and have important implications in the speciation processes of marine species (e.g. Wares \& Cunningham 2001; Waters \& Roy 2003; Jolly et al. 2005; Hunter \& Halanych 2008; Maggs et al. 2008; Zulliger et al. 2009). The influence of the Atlanto-Mediterranean divide is not completely clear from a genetic point of view, as the patterns observed to date vary with the species studied and the molecular markers used (e.g. Chevolot et al. 2006; Pérez-Losada et al. 2007; Calderon et al. 2008; Palero et al. 2008; BorreroPérez et al. 2011); hence, the significance of this transition for the distribution of species still remains controversial (Borsa et al. 1997; Cimmaruta et al. 2005; Patarnello et al. 2007). Integrating information across a wide range of animal groups with different life history parameters is required for a more comprehensive understanding of the effects of historical events and current barriers on the genetic divergence of the marine fauna in the AtlantoMediterranean area. Unfortunately, some taxonomic groups remain largely unexplored. A conspicuous example is the echinoderms, for which only a few species have been genetically analysed along the Atlanto-Mediterranean transition (Duran et al. 2004; Baus et al. 2005; Boissin et al. 2008, 2011; Calderon et al. 2008; Zulliger et al. 2009; Maltagliati et al. 2010; Pérez-Portela et al. 2010; BorreroPérez et al. 2011).

The few available studies on the phylogeography of brittle stars worldwide suggest the existence of genetic barriers, and cryptic speciation processes (Sponer et al. 2001; Le Gac et al. 2004; Muths et al. 2006, 2009; Boissin et al. 2011), even in species with long dispersal potential (Hunter \& Halanych 2010). In the Atlanto-Mediterranean zone, the controversial species complex in the genus Ophiothrix provides an interesting model, consisting of two nominal species described in the area (Koehler 1921; Guille 1964): O. fragilis (Abildgaard, 1789) and O. quinquemaculata (Delle Chiaje, 1828). Ophiothrix spp. are important components of the deep sea benthos along the Northeast Atlantic and Mediterranean, forming dense 'sea beds' (Guille 1964; Broom 1975; Fedra et al. 1976) of up of 2000 animals per square metre in the English Channel (Davoult 1989) that feed on detritus and plankton particles (Warner \& Woodley 1975; Davoult 1989; Davoult \& Gounin 1995). The genus Ophiothrix has attracted particular attention from taxonomists due to its high morphological variability. Ophiotbrix fragilis was originally described as widely distributed, living in the Northeastern 
Atlantic Ocean from the intertidal to subtidal $(300 \mathrm{~m}$ depth) and throughout the Mediterranean Sea (Koehler 1921; Tortonese 1965). Koehler (1921) defined O. fragilis as a highly variable species and discriminated four varieties according to this morphological variability: $O$. fragilis echinata, O. fragilis pentaphyllum, O. fragilis lusitanica and $O$. fragilis abildgaardi. The species $O$. quinquemaculata was described as endemic to the Mediterranean (Koehler 1921; Guille 1964; Tortonese 1965; Zavodnik 1976) and restricted to deep soft bottom habitats $(50-250 \mathrm{~m})$ where they form dense aggregations up to 50-250 specimens per square metre, similar to $O$. fragilis in the North Atlantic (Guille 1964; Fedra et al. 1976). However, to date, all morphological descriptions exhibit overlap values for quantitative characters used to distinguish between species, a lack of clear-cut characters to discriminate among varieties, and considerable variability within the distribution range of each species. Two recent molecular studies have addressed the taxonomic status of Ophiotbrix spp. in the Atlanto-Mediterranean area using two different genes (Baric \& Sturmbauer 1999; Muths et al. 2009). In both studies, two genetic lineages were found that were unrelated to the traditional morphological classification of species or varieties. The first authors (using sequences of the $16 \mathrm{~S}$ rRNA gene of 14 individuals from the Adriatic and the Irish Sea) found that the two genetic clades of Ophiothrix had individuals attributable to both $O$. fragilis and $O$. quinquemaculata and concluded that these taxa corresponded to two different ecotypes of the same species rather than two taxonomic units (Baric \& Sturmbauer 1999). The two clades occurred sympatrically in the Adriatic Sea. The second study (using sequences of the COI gene and allozymes from individuals mostly in the Northeast Atlantic) demonstrated little differentiation between $O$. fragilis varieties in the Atlantic and the existence of a significant genetic break separating the southern populations (both sides of the Iberian Peninsula) from the northern populations in the Atlantic (Muths et al. 2009). No further conclusions about the taxonomic status of these lineages were proposed, and the correspondence between the 16S rRNA and the COI genetic clades found in these studies remains unclear.

The present work aimed to clarify the taxonomic status and distribution of the $O$. fragilis/O. quinquemaculata complex along the South European coast by defining coherent groups based on genetic data and morphology. We also wanted to analyse the phylogeographic patterns and population genetic structure of the main clade found, with special attention to a possible role of the AtlantoMediterranean break, in an effort to determine historical and contemporary processes involved in the genetic diversification of Ophiotbrix spp. In order to relate our findings to previous studies and investigate the coherence of groupings obtained in these works, we sequenced the two mitochondrial genes previously used (16S rRNA and COI genes). Because we have mainly analysed shallow littoral specimens, we opted to refer initially to the species in this study as $O$. fragilis.

\section{Material and methods Sampling}

Samples of Ophiotbrix fragilis were collected between 2006 and 2011 from 13 different localities (Fig. 1 and Table 1); four of them from the Northeast Atlantic coast [Roscoff (ROS), Ferrol (FER), Cascais (CAS) and Armaçao de Pera (APA)], one from the Atlanto-Mediterranean transition [Ceuta (CEU)], six from the Western Mediterranean [La Herradura (LH), Xábia (XAB), Blanes (BLA), Roses (RS), Cadaqués (CAD) and Alcudia ( $\mathrm{AL})]$ and two from the Eastern Mediterranean [Ladiko (LK) and Kalytea Bay (KB) in Rhodes, Greece] covering a significant range of the species' distribution in Europe. Specimens were either sampled by SCUBA diving (depth between 5 and $25 \mathrm{~m}$ ) or collected by hand from under rocks and boulders in the intertidal. Between nine and 31 brittle stars were obtained per population, totalling 221 specimens. Due to the difficulty of collecting samples from the deeper sublittoral, only two specimens from Blanes dredged at $65 \mathrm{~m}$ depth could be included in the analyses. Individuals were fixed in absolute ethanol and preserved at $-20{ }^{\circ} \mathrm{C}$. Tube feet of each individual were removed with forceps under binocular for DNA extraction, and the whole individuals were kept for morphological observation.

\section{DNA analysis}

Total DNA was extracted using a REDExtract-N-Amp kit (Sigma-Aldrich, http://www.sigma.com) from tube feet. Fragments of two mitochondrial genes, the cytochrome oxidase subunit I and the 16S rRNA genes (hereafter COI and 16S), were amplified and sequenced. Universal primers for COI described in the study by Folmer et al. (1994) were initially used for the amplification. In order to increase the quality of sequencing reactions, we used the reverse primer (OF-COIr) from the study by Muths $e t a l$. (2009) and designed a new forward primer from the first sequences available with the software PRIMER vs. 3.0 (http://fokker.wi.mit.edu/primer3/input.htm) as follows: FRAF: 5' ATTTTATATTTGGTGCTT $3^{\prime}$. For the $16 \mathrm{~S}$ gene, we also designed specific primers from sequences of O. fragilis available in GenBank as follows: 16Sofi_F 5' CAGTACTCTGACTGTGCAA $3^{\prime}$ and 16Sofi_R $5^{\prime}$ GGAAACTATGATCCAACATC 3'. PCR amplification reactions were performed in a $20-\mu \mathrm{L}$ total reaction volume with $10 \mu \mathrm{L}$ of REDExtract-N-ampl PCR reaction mix 


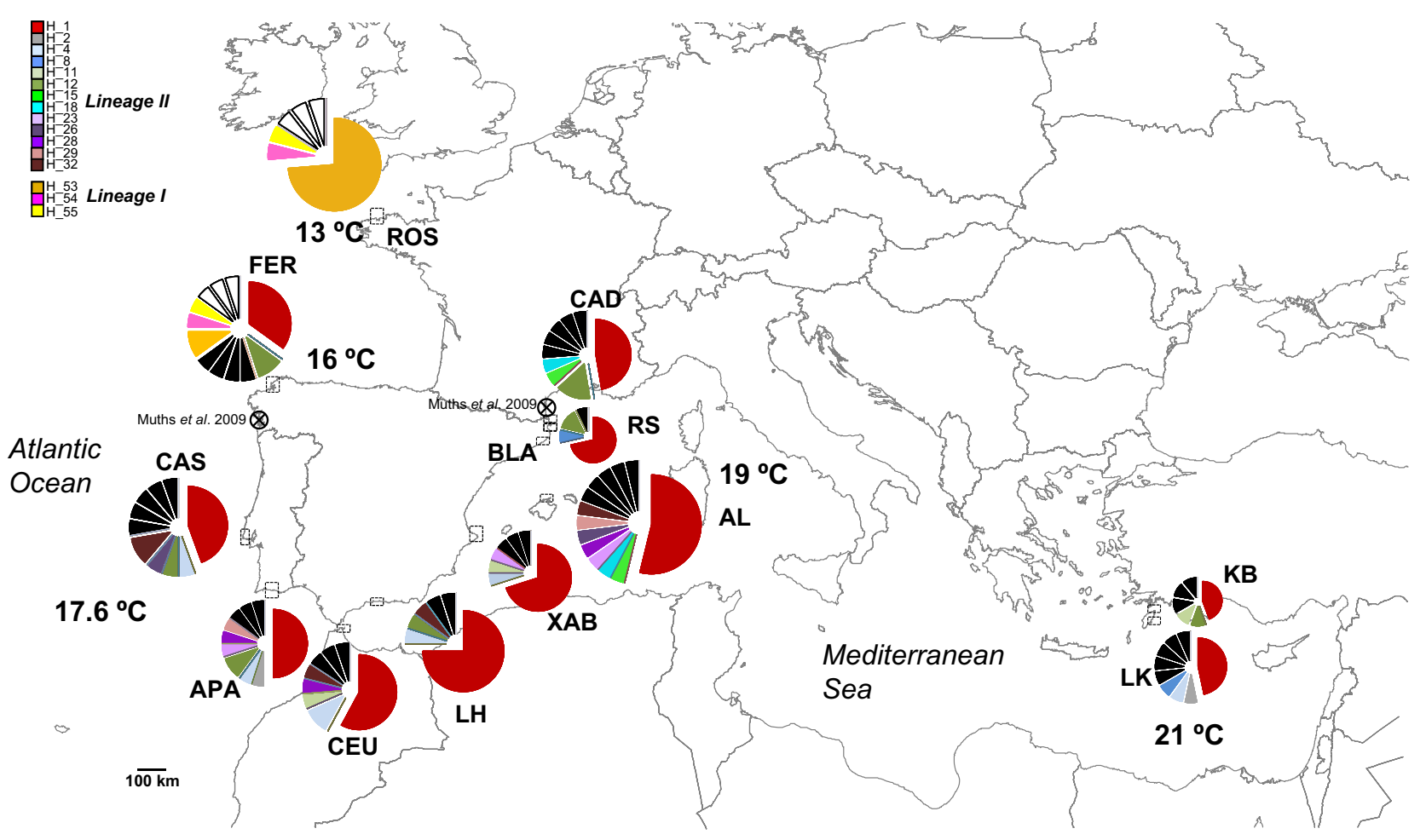

Fig 1 Map of the sampling scheme for Ophiotbrix spp. Pie charts represent haplotypes frequencies of the 16S gene for each population, and pie size is proportional to sample size. Private haplotypes for each population are represented in white or black for Lineage I and Lineage II, respectively. Collection sites at the Iberian Peninsula by Muths et al. (2009) are marked by a crossed circle. Yearly average of sea surface temperature is also presented on the map. ROS, Roscoff; FER, Ferrol; CAS, Cascais; APA, Armaçao de Pera; CEU, Ceuta; LH, La Herradura; XAB, Xábia; BLA, Blanes; RS, Roses; CAD, Cadaqués; AL, Alcudia; LK, Ladiko; and KB, Kalytea Bay.

(Sigma-Aldrich, http://www.sigmaaldrich.com), $0.8 \mu \mathrm{L}$ of each primer $(10 \mu \mathrm{M}), 4.4 \mu \mathrm{L}$ of ultrapure water (SigmaAldrich) and $4 \mu \mathrm{L}$ of template DNA. A single step at $94^{\circ} \mathrm{C}$ for 7 min was followed by 35 cycles (denaturation at $94{ }^{\circ} \mathrm{C}$ for $30 \mathrm{~s}$, annealing at $48{ }^{\circ} \mathrm{C}$ for $30 \mathrm{~s}$ and extension at $72{ }^{\circ} \mathrm{C}$ for $35 \mathrm{~s}$ ) and a final extension at $72{ }^{\circ} \mathrm{C}$ for $7 \mathrm{~min}$ on a thermal cycler (BioRad Mycycler, http:// www.biorad.com). The PCR products were purified and sequenced by Macrogen, Inc. (Seoul, Korea) with the same primers used in the amplification reaction.

All sequences were edited and aligned using Bioedit Sequence Alignment Editor (Hall 1999) and the results from the alignment verified by eye. Sequences of the haplotypes found in this study have been deposited in GenBank (accession numbers from JX947868 to JX948078) (http://www.genbank.com).

\section{Phylogeography and phylogeny}

Phylogenetic analyses were performed by computing NJ trees based on p-distance and Kimura 2-parameter (K2p); bootstrap analysis (1000 replicates) was used to assess the robustness of the nodes. Two outgroup species were also included in the analyses (O. trilineata and O. caespitosa). To compare our haplotypes with those from previous works, we constructed a phylogenetic tree that included our sequences of $16 \mathrm{~S}$ and those from the study by Baric \& Sturmbauer (1999) that could be unambiguously assigned to a sampling locality and morphology. For the construction of the COI tree in this study, our sequences were pooled with available sequences from the study by Muths et al. (2009) representing both lineages described in that work. Genetic divergence between lineages of Ophiothrix based on the $p$-distance and $\mathrm{K} 2 \mathrm{p}$ models was calculated in MEGA vs. 3.

The complete data sets of sequences obtained in this study for the COI and $16 \mathrm{~S}$ were used to construct unrooted networks, under the null hypothesis of no genetic differentiation among populations. We used the Network vs. 4.5.1.0 program (http://www.fluxus-engineering.com/ sharenet.htm), which assumes the median-joining network method in the absence of recombination (Bandelt et al. 1999). This method begins by combining the minimum 


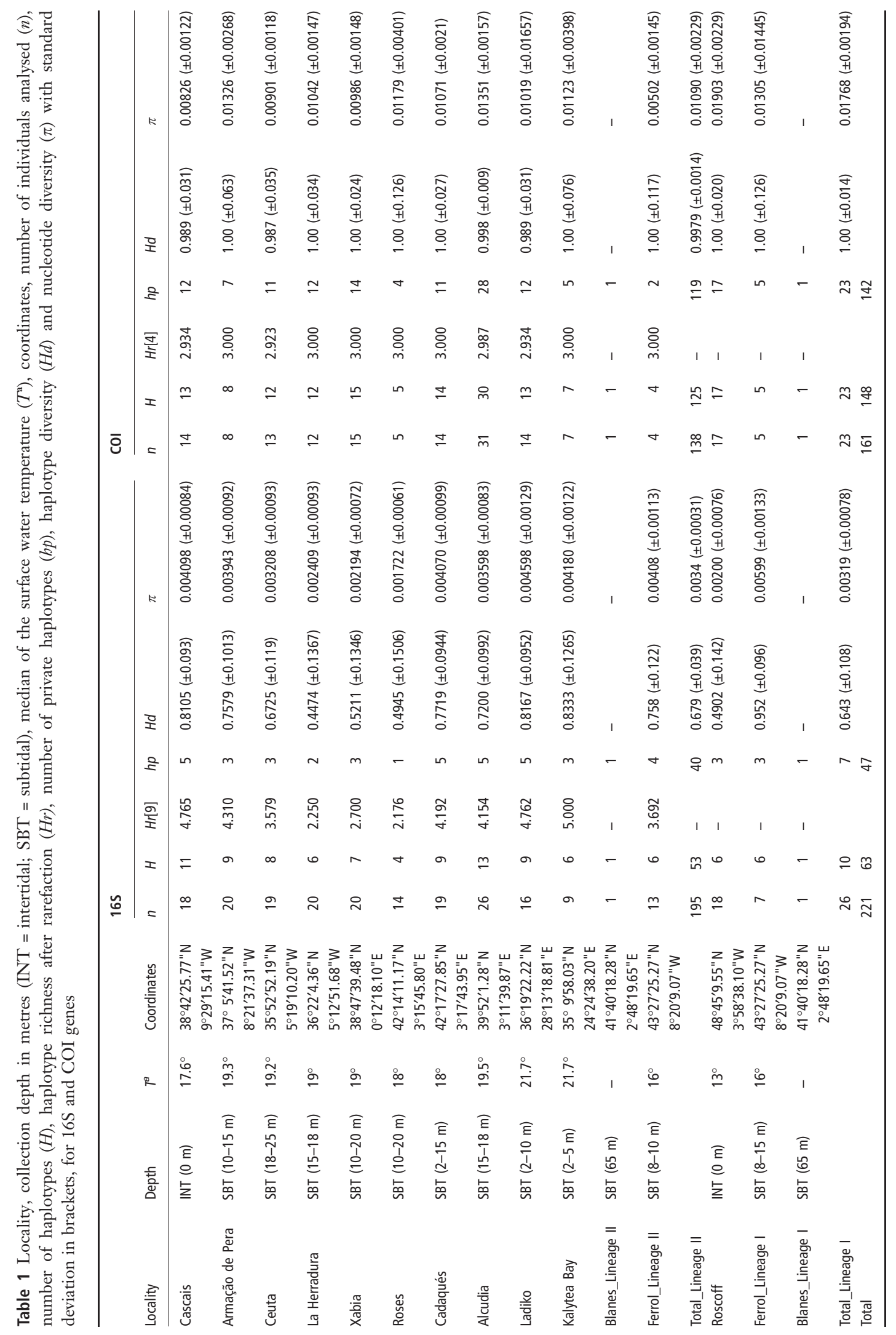


spanning trees within a single network. With a parsimony criterion, median vectors ('mv', which represent missing intermediates haplotypes) are added to the network. The loops observed in the networks were solved using the criteria derived from coalescent theory (Templeton et al. 1987; Templeton \& Sing 1993).

\section{Demographic analysis}

The history of effective population size was tested by the mismatch distribution for both markers, analysing the distribution of pairwise differences among all haplotypes in a sample following the models of Rogers \& Harpending (1992) and Rogers (1995) in Arlequin vs. 3.1. The mismatch method is based on the assumption that stable population sizes are reflected by a multimodal distribution of pairwise differences, while recent population growth leaves a characteristic signature in the DNA sequences in the form of a unimodal distribution of pairwise differences in the samples. We assessed the fit of mismatch distributions to the theoretical distribution expected in an expansion scenario by simulation. The raggedness index $(r)$ and its significance were computed for each population.

The history of effective population size was also assessed by means of other statistics (neutrality tests) such as Tajima's $D$, Fu's $F s$ (Fu 1997) and $R^{2}$ tests (Ramos-Onsins \& Rozas 2002) using DnaSP vs. 5.10 (Librado \& Rozas 2009). Analyses were performed for populations as well as for different lineages of Ophiotbrix.

\section{Population genetic analyses}

In order to avoid mixing two different genetic pools, population genetic analyses were performed only on the best represented lineage (Lineage II, see below). Numbers of haplotypes $(H)$, private haplotypes $(h p)$ haplotype diversity $(H d)$ and nucleotide diversity $(\pi)$ values were obtained with DnaSP vs. 5.10. Haplotype richness $(\mathrm{Hr} r$ was also calculated for the $16 \mathrm{~S}$ and COI of Lineage II populations after rarefaction (to the minimum sample size) with the software CONTRIB (Petit et al. 1998). An analysis of molecular variance (AMOVA) using pairwise sequence differences was performed to examine the population structure, and its significance was tested running 16000 permutations in Arlequin vs. 3.1 (Excoffier et al. 2005). Populations were grouped within Atlantic and Mediterranean basins following our prior expectation of a genetic subdivision caused by the 'basin boundary'. For further analyses of population genetic structure, genetic distances $\left(F_{S T}\right)$ between populations based on pairwise differences were assessed. The significance of the values was evaluated by performing 10000 permutations with the same software. The new measure of differentiation $D$ proposed by Jost (2008) was also obtained using the esti- mator in eq. 13 of Jost (2008) with the SPADE software (available at http://chao.stat.nthu.edu.tw), with 1000 bootstrap replicates used to estimate confidence intervals. As $D$ is based on haplotype frequencies and the Fst measure adopted uses pairwise sequence differences, we could compare the information gleaned from both types of estimators. Analyses were run for the $16 \mathrm{~S}$ and COI separately. A false discovery rate (FDR) correction was applied to the $P$-values (B-Y method as described in Narum 2006) to account for multiple tests. In the case of $D$, the width of the confidence interval was adjusted to the corrected $\mathrm{p}$ and, if it included the 0 value, no significant differentiation was inferred. Additionally, we ran a discriminant analysis of principal components (DAPC, Jombart et al. 2010) for both markers together to assess genetic structure using populations as groups with the adegenet package (Jombart et al. 2008) for the $\mathrm{R}$ software. DAPC is a multivariate technique that extracts information from genetic data sets (multivariate in nature) by first performing a principal component analysis (PCA) on predefined groups (populations in our case) and then using the PCA factors as variables for a discriminant analysis (DA), which seeks to maximize the intergroup component of variation. The initial PCA step ensures that the input variables for the subsequent DA are uncorrelated. This method allows the visual identification of genetic clusters of individuals and can outperform more computer-intensive Bayesian clustering approaches in detecting genetic substructure (Jombart et al. 2010).

\section{Results}

\section{Genetic diversity}

For the mitochondrial $16 \mathrm{~S}$ gene, we obtained $319 \mathrm{bp}$ from 221 individuals collected from 13 localities (see Fig. 1 and Table 1). One gap was necessary for the alignment between sequences of the lineages found. A total of 57 variable sites (26\%) and 63 haplotypes were found from all the sequences of this gene fragment (Table 1). Of the total haplotypes detected, 47 (74\%) were private and the number of private haplotypes per population ranged from one (Roses, RS) to seven (Ferrol, FER). Haplotype diversity $(H d)$ and nucleotide diversity $(\pi)$ ranged from 0.490 to 0.952 and from 0.0017 to 0.0059 , respectively (Table 1 ).

For the COI gene, we obtained sequences of $797 \mathrm{bp}$ from 161 individuals (Table 1). Two hundred and sixty-six sites were polymorphic (33\%), and 148 haplotypes were detected. Forty-eight of the variable sites had non-synonymous substitutions, and most of the haplotypes were private (99\%). Haplotype diversity $(H d)$ and nucleotide diversity $(\pi)$ ranged from 0.989 to 1.000 and from 0.010 to 0.019 , respectively (Table 1). The highest values of haplotype richness were detected in the Greek populations. 

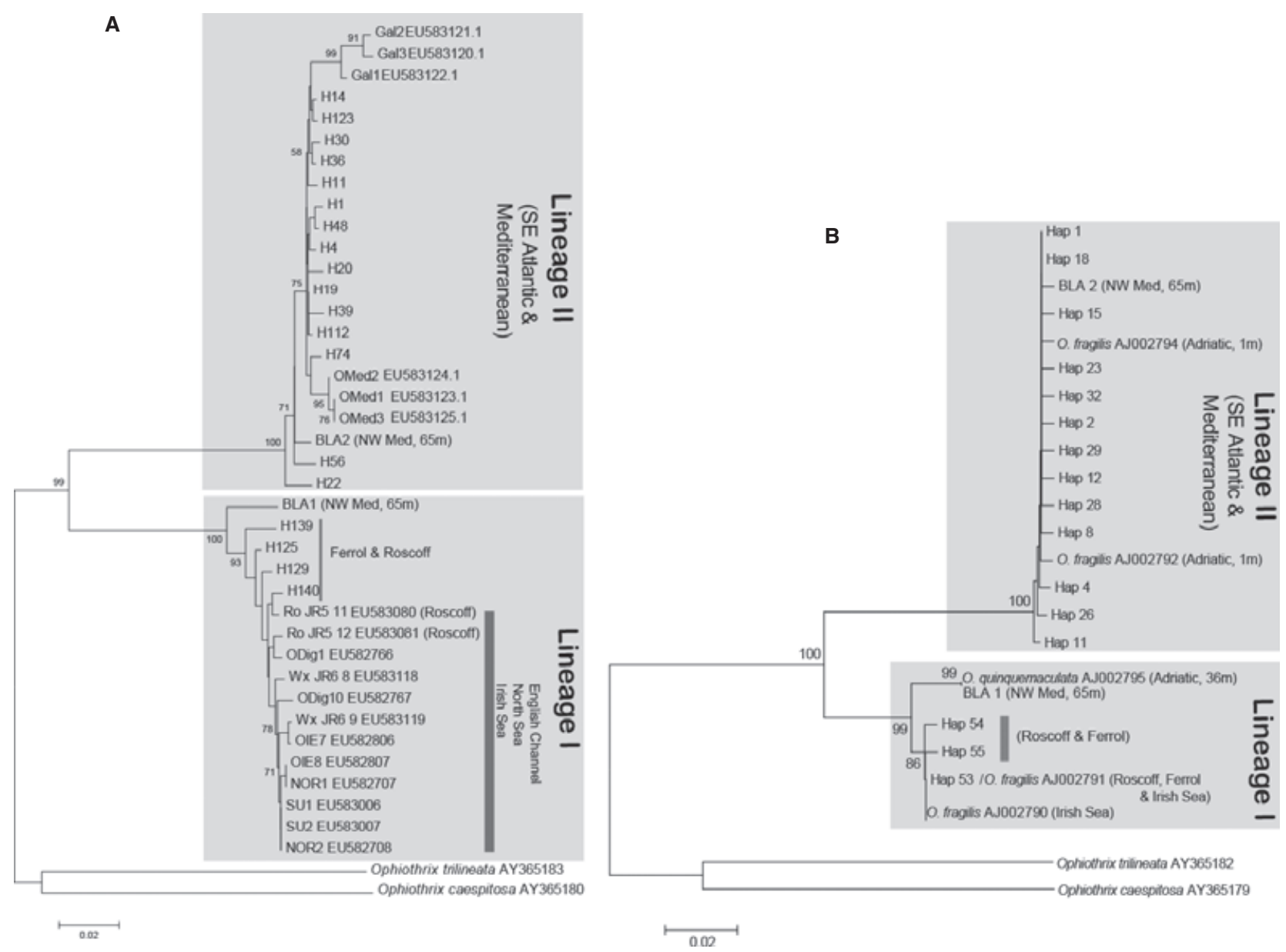

Fig 2 Simplified version of the phylogenetic trees constructed by neighbor joining based on the $p$-distances model. -A. From our most representative COI haplotypes, with representative sequences from Muths et al. (2009) included (with locality code and accession number from that work) -B. From our most common 16S haplotypes, with sequences from Baric \& Sturmbauer (1999) included (with name, locality code and accession number corresponding to that work). Individuals from Blanes are highlighted as BLA1 and BLA2. BLA1 and O. quinquemaculata AJ002795 were the same haplotype, and the same happens with $\mathrm{H} 53$ and O. fragilis AJ002791. Values presented on the branch nodes correspond to bootstrap percentages after 1000 replicates, when higher than $50 \%$.

\section{Phylogeny and phylogeography}

Phylogenetic trees computed from the p-distance and Kimura 2-parameter (K2p) models showed equal topology and node support values. Both the $16 \mathrm{~S}$ and the COI sequences grouped into two monophyletic clades with high bootstrap support values (99-100\%) that we refer to as Lineage I and Lineage II. Simplified versions of these phylogenies (Fig. 2) highlight these distinct lineages and include the most representative and frequent sequences from our study and previous works. The full list of haplotypes is presented in Table S1, including population frequencies and lineage assignment. Lineage I and Lineage II were geographically separated in our samples in the shallow sublittoral, but they overlapped in the NW of the Iberian Peninsula (FER, Galicia). Interestingly, the two individuals collected from the deep sublittoral $(65 \mathrm{~m})$ in Blanes (BLA, W Mediterranean) corresponded to one of each of the two lineages. It should be noted that the clades were coherent across genes: individuals that belong to one lineage based on one gene also belong to the same lineage based on the other gene.

For the COI, Lineage I included the sequences from Roscoff (English Channel), some from Ferrol and one juvenile collected at $65 \mathrm{~m}$ depth in Blanes (NW Mediterranean). They grouped together with those from the English Channel, Irish Sea and North Sea included in the study by Muths et al. (2009) as their 'northern lineage'. All the other sequences formed Lineage II, including those from the rocky shallow littoral of southern Europe (Atlantic and Mediterranean) and one of the specimens 
A

$16 S$

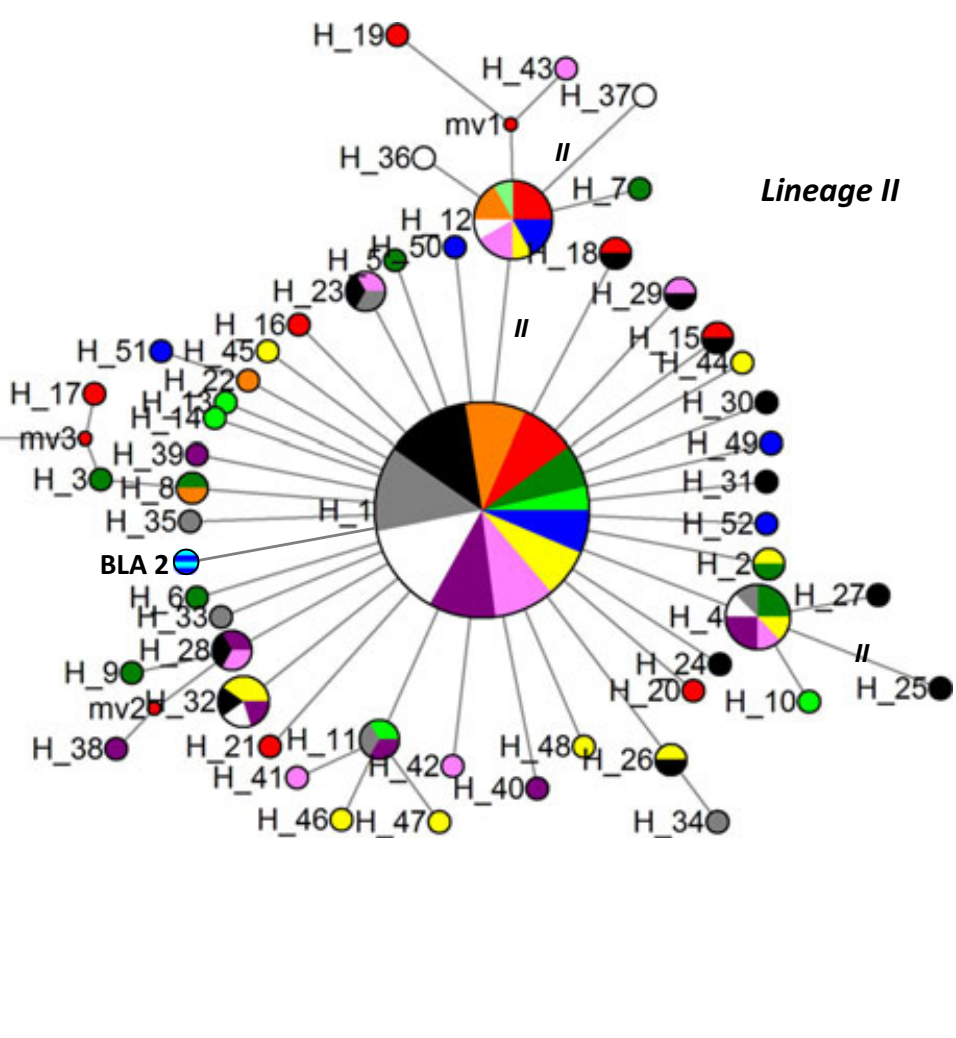

B

Lineage I

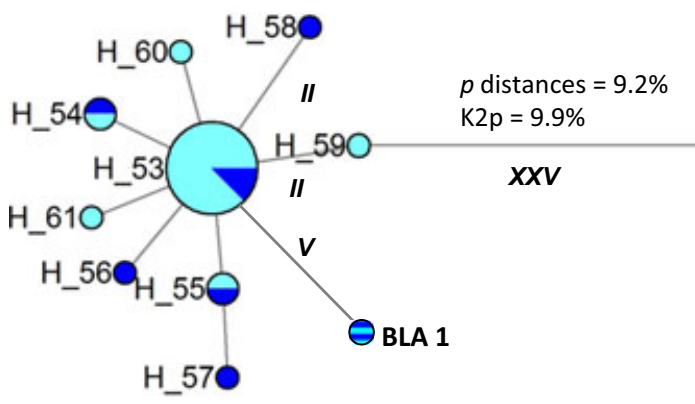

$\begin{array}{ll}\square \text { LADIKO } & \square \text { CEUTA } \\ \square \text { KALYTEA } & \square \text { ARMAÇÃO DE PERA } \\ \square \text { CADAQUÉS } & \square \text { CASCAIS } \\ \square \text { ROSES } & \square \text { FERROL } \\ \text { ALCUDIA } & \square \text { ROSCOFF } \\ \square \text { XABIA } & \text { B BLANES }(65 \mathrm{~m})\end{array}$

\section{COI}
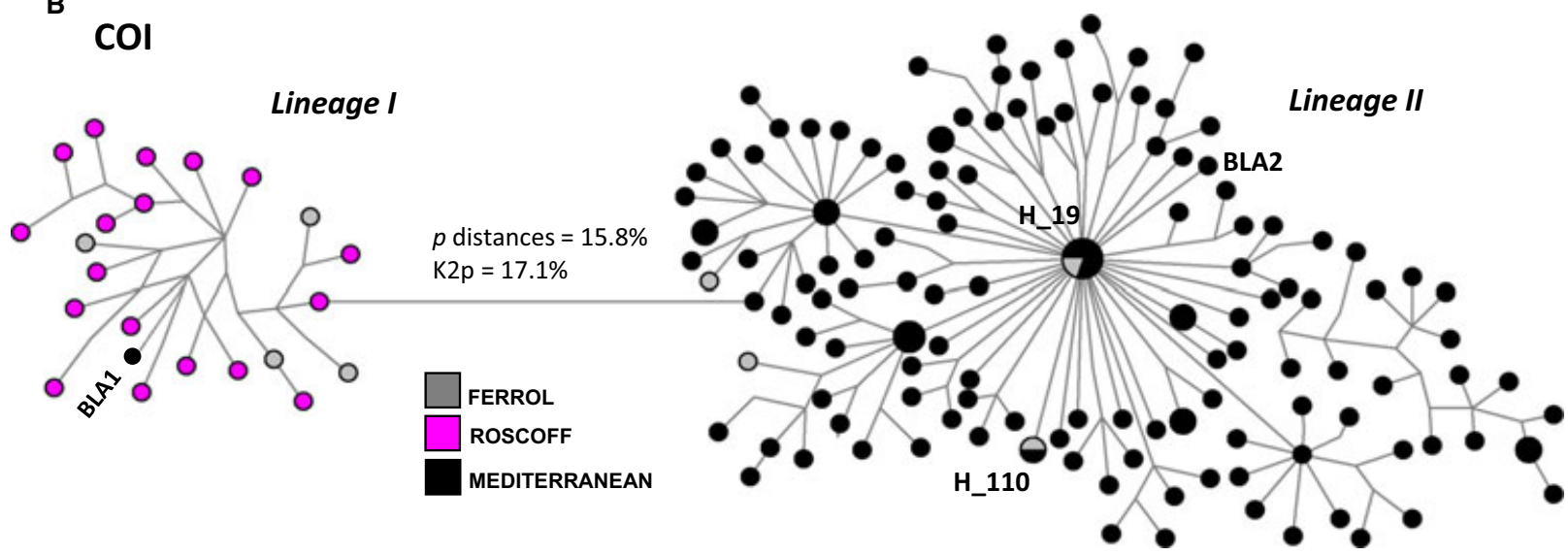

Fig 3 Median-joining haplotype network for Ophiothrix spp. Areas of the circles are proportional to the number of sampled individuals. Lineage divergences are indicated by the $p$-distance and Kimura 2-parameter (K2p) models. -A. From 16S fragments; partitions inside the circles represent the proportion of each population within each haplotype; red dots named as 'mv' represent missing, probably unsampled, haplotypes or extinct sequences; lines between circles represent one mutational step, and roman numerals are the number of mutations between haplotypes. - B. From COI fragments; individuals from Ferrol, Roscoff and Mediterranean locations are highlighted in grey, pink and black colour, respectively. Individuals from Blanes are highlighted as BLA1 and BLA2.

from Blanes dredged at $65 \mathrm{~m}$. The 'southern lineage' sequences of Muths et al. (2009) also belong to this clade (Lineage II). Lineage divergence was about $16 \%$ for the COI. Divergence between these two lineages was compa- rable to values of divergence between sequences of other species of the genus available from GenBank (Table S2). The $16 \mathrm{~S}$ gene tree showed similar results. Sequences also grouped into two different lineages matching exactly those 
obtained from the COI sequences with the same geographic repartition, and lineage divergence was about $9 \%$ for the 16S. In addition, our Lineage I (Roscoff, plus part of Ferrol, plus one 'deep' specimen of Blanes) corresponded to Lineage I in the study by Baric \& Sturmbauer (1999), which included O. fragilis samples from the Irish Sea and one haplotype found in three O. quinquemaculata specimens dredged at $36 \mathrm{~m}$ depth in the Adriatic Sea (this was the same haplotype as our Blanes specimen). Our Lineage II included most of the samples from the littoral of southern Europe (between 0 and $20 \mathrm{~m}$ depth, plus one juvenile from Blanes at $65 \mathrm{~m}$ ) and the four haplotypes found by Baric \& Sturmbauer (1999) and assigned to their 'Lineage II'. They consisted of seven specimens from the Adriatic Sea collected either at $1 \mathrm{~m}$ or below $30 \mathrm{~m}$ depth, and assigned to the two nominal species $O$. fragilis and O. quinquemaculata.

Networks constructed from both markers also demonstrated the existence of two sharply divergent lineages lacking intermediate haplotypes (Fig. 3). The $16 \mathrm{~S}$ network had a clear star-like pattern, with numerous low-frequency (mostly private) haplotypes separated by one or a few mutations from ancestral haplotypes in the central position of the networks, and wide geographic distribution and frequency (H_1, H_4 and H_12 for Lineage II and H_53 for Lineage I). The COI network was less structured (particularly in Lineage I), with most sequences at low frequencies or as private haplotypes. The most frequent haplotype (H_19, Lineage II) appeared as an ancestral haplotypes and was represented in the Mediterranean and the Atlantic (Ferrol population). No geographic structure was detected within lineages from the network analyses.

The distance between both lineages was high but different between genes (Fig. 3) due to different mutation rates. Thus, p-distances and $\mathrm{K} 2 \mathrm{p}$ distances between lineages were $9-10 \%$ and $15-17 \%$ for $16 \mathrm{~S}$ and COI, respectively. Results from both phylogenetic and phylogeographic analyses showed the existence of two lineages within the Ophiotbrix spp. complex with comparable values of genetic diversity (see $H d$ and $\pi$ in Table 1 ).

\section{Morphological observations}

We examined morphological characteristics on a subset of brittle stars from both lineages for which we also had genetic information. Samples of Lineage I from Ferrol, Roscoff and Blanes and samples of Lineage II from La Herradura, Xabea, Ferrol and Blanes were included in the analysis. Although some plasticity was detected within lineages, in general, our morphological analyses revealed differences between lineages. The individuals of Lineage I always had rounded discs, ranging in diameter between $7.1 \mathrm{~mm}$ and $10.6 \mathrm{~mm}$ for adult individuals. The dorsal (aboral) side of the disc presented wide, naked radial shields (covering approximately $1 / 2$ of the disc area) and
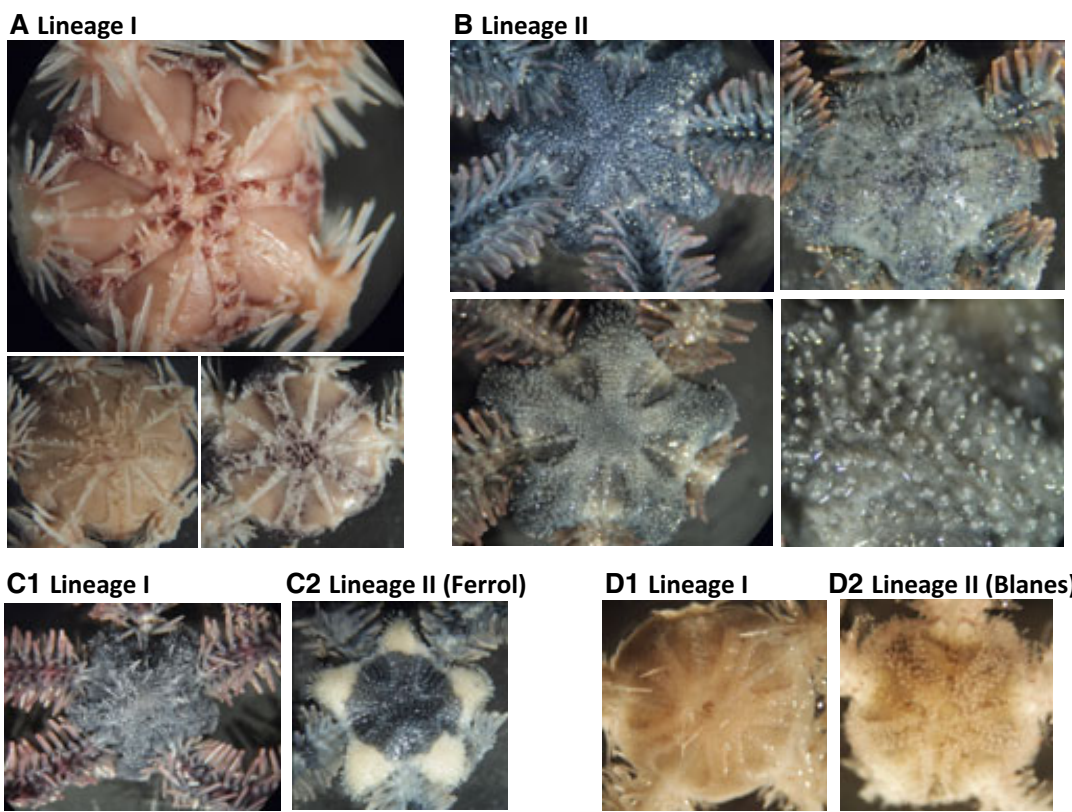

C2 Lineage II (Ferrol)

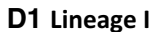

D2 Lineage II (Blanes)
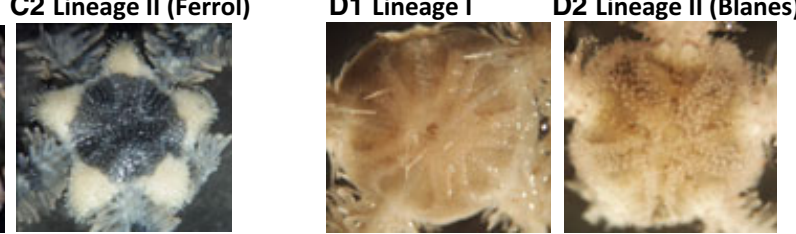

Fig. 4 Pictures of Ophiothrix spp. Dorsal side of the disc. -A. Lineage I; three different specimens from Roscoff (Atlantic Ocean). -B. Lineage II; three different specimens from the Mediterranean sea and the detail of disc spines. $-\mathrm{C}_{1}$ and $\mathrm{C}_{2}$. Specimens of Lineage I and II from Ferrol. $-\mathrm{D}_{1}$. and $\mathrm{D}_{2}$. Juveniles of Lineages I and II from Blanes collected at $65 \mathrm{~m}$ depth (Mediterranean Sea). 
always featured some slender spines in the central area of the disc, along the inter-radial fields and in the narrow field separating pairs of radial shields. Small tubercles and spinelets also dotted these areas. Colour was, in general, pale, including pink, purple and white-beige tinges (Fig. 4). The single specimen of Lineage I from Blanes (BLA1) collected at $65 \mathrm{~m}$ depth was a small juvenile $(>1 \mathrm{~mm})$ with long spines and naked shields that corresponded to its genetic lineage (Fig. 4D 1 ).

Specimens from Lineage II displayed the variability in disc shape, which depended on the gonad development, but they were in general pentagonal. Disc diameter in adults varied between $6.5 \mathrm{~mm}$ and $10.6 \mathrm{~mm}$ for the individuals assessed. The radial shields at the dorsal side of the disc were small (approximately $1 / 3-1 / 4$ the disc area) and partially covered by small spines or tubercles. The radial and central area of the dorsal side of the disc was always homogeneously covered by small spines ending in 3-4 points (Fig. 4). These spines sometimes became longer on the border of the disc. These characters were also observed in the juvenile (BLA2) dredged at $65 \mathrm{~m}$ depth from Blanes (Fig. 4D2).

Some morphometric characters could be also measured and compared between lineages. In general, we observed longer arms in relation to disc diameter in Lineage I. The relationship arm length/disc diameter was $5.017 \pm 0.304$ (mean \pm SE) in Lineage I and $6.365 \pm 0.325$ in Lineage II, respectively. The differences in this parameter were significant ( $t$-test, $P=0.006$ ). On the other hand, the number of arm spines did not differ between both lineages. We found from six to 10 spines, and between seven and 10 in Lineages I and II, respectively, as measured on the third free arm segment beyond the disc edge. However, the length of the arm spines, as measured in the second dorsal spine from the same segment of the arms, was higher ( $t$-test, $P<0.001)$ in samples of Lineage I $(2.525 \pm 0.081 \mathrm{~mm})$ than in samples of Lineage II $(1.983 \pm 0.090 \mathrm{~mm})$. There- fore, individuals from Lineage I presented a more 'brittle' and more 'spiny' shape (Table 2). Interestingly, our Lineage I specimens (frequent in the northern Atlantic) more closely resemble morphological descriptions of O. quinquemaculata (Guille 1964; Tortonese 1965).

It is noteworthy that some intermediate morphologies could be observed in the area where the two lineages were found together (Ferrol in the Atlantic). Thus in Ferrol, while individuals belonging to Lineage II displayed the typical disc morphology, brittle stars from Lineage I had smaller radial shields and wider fields of small spines and tubercles than usual for this lineage. However, they did have the characteristic long spines arising from these fields (see Fig. $4 \mathrm{C}_{1}$ and $\mathrm{C}_{2}$ )

\section{Demographic events and population genetics of Lineage II}

The three neutrality tests computed for both genes (each population, lineage and the whole data set) detected a past demographic expansion $\left(P<0.05\right.$ for Fu's $F$, Rozas' $R^{2}$ and Tajima's $D$ tests) (See detailed results for each test in Table S3). The mismatch distribution parameters were also in agreement with a sudden expansion, resulting in a characteristic unimodal distribution of pairwise differences (Fig. S1).

In order to avoid mixing different genetic pools, population genetics analyses were performed only for Lineage II. We focused on Lineage II because it was the most abundant lineage in South Europe, the area preferentially sampled in this study. Estimates of the approximate time of demographic expansion in generations ( $t$ ) for Lineage II were calculated by the equation ' $\mathrm{T}=2 \mathrm{ut}$ ' (Rogers \& Harpending 1992), where ' $T$ ' is the date of the growth or decline measured in units of mutational time and ' $u$ ' is the mutation rate per sequence and per generation. The value of $\mathrm{u}$ was calculated from ' $\mathrm{u}=2 \mathrm{lk}$ ', where ' $\mathrm{l}$ ' is the mutation rate per nucleotide and ' $\mathrm{k}$ ' is the number of nucleotides of the analysed fragment. The estimation from this

Table 2 Main morphological features and distribution of Ophiothrix spp. Genetic lineage, disc colour, disc shape, maximum and minimum value of the relationship between arm length and disc diameter (A/D), disc spine shape, features of radial area, maximum and minimum values of spine length (second dorsal spine from the third free arm segment beyond the disc edge) and localities where they were collected

\begin{tabular}{|c|c|c|c|c|c|c|c|}
\hline Lineage & Colour & Disc shape & $\mathrm{A} / \mathrm{D}$ & Disc spines & Radial shields & Spine length & Localities \\
\hline I & $\begin{array}{l}\text { Pink, pale pink, purple, beige, } \\
\text { white and/or whitish, }\end{array}$ & Rounded & $0.720-0.567$ & Large & Wide and naked & $3.1-2.1 \mathrm{~mm}$ & $\begin{array}{l}\text { Intertidal Roscoff \& Ferrol } \\
\text { and Blanes (65 m depth). }\end{array}$ \\
\hline ॥ & $\begin{array}{l}\text { Grey, brown, blue, dark blue } \\
\text { and/ or reddish }\end{array}$ & Pentagonal & $0.652-0.361$ & $\begin{array}{l}\text { Short spinelets, } \\
\text { three-four pointed } \\
\text { homogenously } \\
\text { distributed }\end{array}$ & $\begin{array}{l}\text { Small, partially } \\
\text { covered } \\
\text { by tubercles }\end{array}$ & $2.5-1.2 \mathrm{~mm}$ & $\begin{array}{l}\text { Intertidal and shallow subtidal } \\
\text { South Europe (Ferrol, Cascais, } \\
\text { Armaçao de Pera) and Mediterranean } \\
\text { (Ceuta, La Herradura, Xabia, Alcudia, } \\
\text { Roses, Blanes, Cadaqués, Ladiko, } \\
\text { Kalytea Bay). }\end{array}$ \\
\hline
\end{tabular}




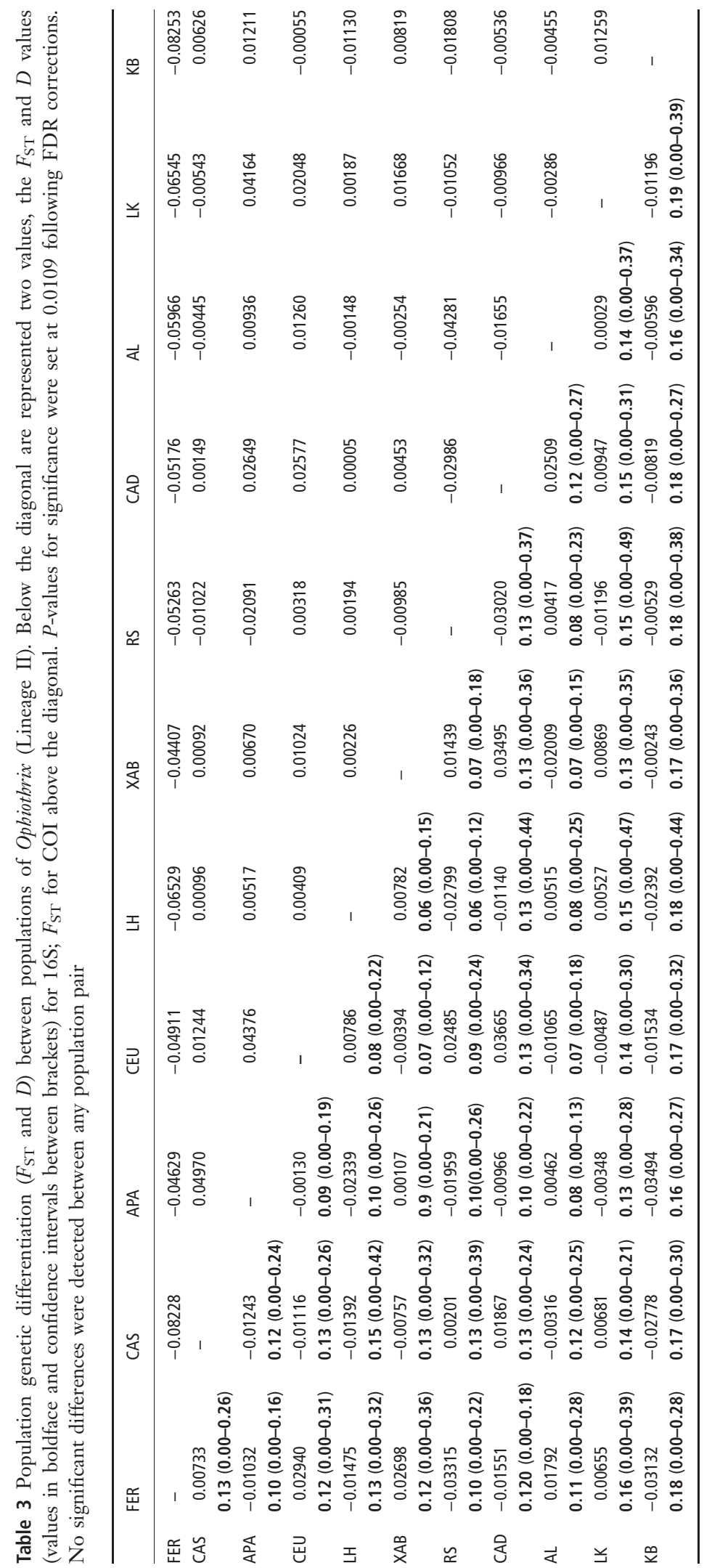


fragment suggested that demographic expansion happened about 250.000 generations ago when a mutation rate of $3.5 \%$ per one million years was applied (Lessios et al. 1999).

AMOVA results based on grouping populations of Lineage II into Atlantic and Mediterranean zones revealed that almost $100 \%$ of the genetic variability was retained within populations and no significant differences in genetic structure between basins for either gene $\left(F_{\mathrm{CT}}=-0.00067\right.$, $P=0.483$ and $F_{\mathrm{CT}}=-0.00254, P=0.790$ for $16 \mathrm{~S}$ and COI, respectively, Table S4).

Further analyses based on pairwise comparisons among populations using the $F_{S T}$ and $D$ estimators confirmed the AMOVA results, with no significant differences detected between any pair of populations for 16S (Table 3). Likewise, no significant differentiation was found with $F_{\mathrm{ST}}$ for COI. Results from the $D$ estimator for the COI were not conclusive (and hence not shown in Table 3) because most of the haplotypes were private, and thus, estimates of differentiation based on haplotype frequencies were mostly 1 . This is assumed to reflect large population sizes (see Discussion) rather than true isolation between populations.

Overall, there were no genetic differences based on geographic origin, and Lineage II seemed to be a panmictic population at the scale studied. The DAPC analysis graphically depicts the interpopulation structure using both markers in Lineage II (Fig. S2). The pattern of overlap in most populations is in agreement with the lack of differentiation found, although this analysis could detect a subtle structure, with a separation (albeit incomplete) in the first axis of one of the Greek (Ladiko) populations. Greek populations were generally the most diverse for the $16 \mathrm{~S}$ gene.

\section{Discussion}

One of the most distinctive findings from our study was the existence of two highly divergent lineages of Ophiothrix, which likely correspond to two unrecognized species. Our study completed and clarified the picture resulting from previous works (Baric \& Sturmbauer 1999; Muths et al. 2009) by showing that these previous results with different gene markers were compatible and coherent with our findings. First, our two genetic partitions had the same phylogenetic signal, with Lineages I and II obtained from one gene matching exactly the ones obtained from the other. Second, there is a correspondence between our Lineage I and Lineage I (16S data) of Baric \& Sturmbauer (1999) and the northern lineage (COI data) of Muths et al. (2009). Likewise, our Lineage II corresponded to Lineage II and the southern lineage described in these previous works. Third, our study completes the geographic distribution map of these lineages. The first work by Baric \& Sturmbauer (1999) had only 14 individuals, mostly from the Adriatic Sea. One of their clades (Lineage I in our terminology) was Atlanto-Mediterranean. The other (Lineage II) was exclusively Mediterranean. Muths et al. (2009) sampled mostly NE Atlantic populations, which featured Lineage I (our terminology) individuals, while two samples of the Iberian Peninsula, one from the Mediterranean and the other from the Atlantic (Galicia), belonged to Lineage II. Our samples spanned from the English Channel to the Atlanto-Mediterranean transition to the Eastern Mediterranean. We show that Lineage I was found in the shallow sublittoral in the Atlantic but also in deeper communities in the Mediterranean (as shown by our specimen from Blanes at $65 \mathrm{~m}$ depth and the three individuals dredged in the Adriatic by Baric \& Sturmbauer 1999), while Lineage II was found in the Mediterranean and in the Iberian Atlantic shores, overlapping with Lineage I in the NW of the Iberian Peninsula (Galicia). It is likely that Muths et al. (2009) did not find specimens from Lineage I in their Galician population due to their small sample size $(n=6$ for the whole Iberian Peninsula).

The threshold to distinguish species using molecular divergence data is variable among animal groups (Avise 1994; Lee 2004), and comparison with closely related taxa is necessary (Hebert et al. 2003). The level of genetic divergence between the two lineages found in this study was high (about $15.8-17 \%$ and $9.2-9.9 \%$ for COI and $16 \mathrm{~S}$, respectively). This level of COI divergence is similar to genetic distances found between Ophiothrix lineata, $O$. trilineata and $O$. aristulata (about 17\%). Within the Echinodermata, there is a wide range of intra- and interspecific variability for COI and $16 \mathrm{~S}$ genes (see Hart et al. 1997; Uthicke \& Benzie 2003; Waters \& Roy 2003; Waters et al. 2004; Hart \& Podolsky 2005; Uthicke et al. 2010). Interspecific genetic distances for the brittle star genus Macrophiothrix ranged from 1.7 to $25.4 \%$ for COI and around a 3\% for 16S (Hart \& Podolsky 2005). Genetic divergence between cryptic species of the brittle star Acrochnida brachiata was ca. $19 \%$ for the COI gene (Muths et al. 2006), and divergences for this gene among cryptic species of Ophioderma longicauda were 2.2-10.2\% (Boissin et al. 2011). Therefore, the divergences observed between the two lineages of Ophiothrix lie well within the interspecific range of divergence values in ophiuroids, while at the same time differences with outgroup Ophiothrix species are higher, all supporting the existence of two recently-diverged, sibling species in the area.

The genetic clades of Ophiothrix are seemingly unrelated to traditional morphological distinctions. Baric \& Sturmbauer (1999) assigned their specimens to the two described species, $O$. fragilis and $O$. quinquemaculata, on the basis of morphological characters. The two genetic lineages detected were not coherent with this separation, 
with representatives of both 'species' in both clades. This led these authors to conclude that these taxa are not valid species but rather ecotypes that arose independently in both lineages. Likewise, Muths et al. (2009) identified all their specimens as $O$. fragilis and attempted to sort them, on morphological grounds, into described morphological varieties (i.e. pentaphyllum echinata and abilgaardi varieties). Again, their clades showed no consistent separation among these varieties; rather, their larger clade (corresponding to our Lineage I) included representatives of all morphological varieties separated by $<1 \%$ genetic divergence. Similarly, allozyme frequencies were nearly identical between varieties, albeit with slight differences in two (of seven) loci. These authors considered that the most parsimonious explanation for their findings was that $O$. fragilis was a single, but morphologically plastic, species. Varieties may have arisen as adaptations to different environments, as the slight differences reported in two allozyme loci may reflect different selective pressures if these markers are not strictly neutral. A more complete genetic sampling (with more polymorphic markers) and reproductive cross-breeding trials would be necessary to ascertain whether the different species and varieties described morphologically have any genetic basis or are mere phenotypic variants. Clearly, however, they do not correspond to isolated lineages or to distinct species.

If distinctions based on traditional morphological characters are not supported by genetic clades, we may ask the opposite question of whether there is support, on morphological grounds, for the genetic clades found. The answer seems to be affirmative, because both lineages displayed differences in disc morphology, radial shields size, spines size and distribution, and morphometry; however, these results required confirmation due to the low number of specimens analysed herein. Although some quantitative aspects overlap, there are potentially useful diagnostic characters that deserve further attention; the constant rounded disc shape, wide and naked radial shields and the presence of long spines on the dorsal fields of brittle stars of Lineage I. Having studied mostly shallow littoral specimens, we cannot, at present, assess the full variation in morphological characters in any of the lineages, and this is left pending for future studies. An interesting finding, however, is that in areas where the lineages coexist (in Galicia), some intermediate forms are found (brittle stars corresponding to mitochondrial Lineage I but featuring aspects of Lineage II-like morphology; e.g. Fig. $4 \mathrm{C}_{1}$ ). This strongly suggests, that, in spite of marked genetic divergence, the genomes of both lineages remain partly porous, perhaps in the sense that some introgression from Lineage II to Lineage I is still possible. Clearly, more studies in the areas of overlap are necessary to definitely settle this point.
In addition, the genetic data obtained in this study indicate that the lineage widely distributed along the North Atlantic (Lineage I) belongs to the same species found on deep soft bottoms in the Mediterranean, and an accurate revision of the literature gives further support to this view. First, our specimens from Roscoff (the so-called Lineage I here) were morphologically similar to $O$. quinquemaculata described by Guille (1964) from the deep Mediterranean. Second is the fact that both $O$. fragilis in the North Atlantic and $O$. quinquemaculata on the deep bottoms of the Mediterranean are known to form dense beds (Broom 1975; Fedra et al. 1976; Baric \& Sturmbauer 1999). Moreover, in these dense beds, both $O$. fragilis and $O$. quinquemaculata have the same recruitment behaviour. Larvae recruit directly from the plankton onto the adults of the dense patch and juveniles are normally found on the discs, arms and within genital bursae of the large adults (Guille 1964; Warner 1971; Davoult et al. 1990). In contrast, the 'solitary' form of Ophiothrix (genetically Lineage II), which live under rocks and boulders in the Mediterranean, recruits massively on sponges and other substrates, but never on the adults (Turon et al. 2000).

The divergence between the recovered lineages could be inferred to date back ca. 4.8-7.5 million years, based on mutation rates of $2-3.5 \%$ per million years in echinoderms for COI (Bermingham \& Lessios 1993; Lessios et al. 1999). This estimate places the split approximately at the time of the Mio-Pliocene transition. However, divergence estimations should be interpreted with caution as they provide a very rough indication for the time frame of the split, due to the absence of a specific calibrated clock for ophiuroids. The Mio-Pliocene era was characterized by major climatic, topologic and tectonic changes (Brault et al. 2004). A series of sea-level fluctuations led to a strong continentalization of Western Europe (Meulenkamp \& Sissingh 2003) and to the desiccation of the Mediterranean sea, reduced into a series of hypersaline lakes during the so-called Messinian salinity crisis (6-5.5 Mya) (Maldonado 1985; Duggen et al. 2003). During this period, no marine corridors existed between the NE Atlantic and the North Sea, with the exception of a passage towards the North of the British Isles, and most of the Mediterranean marine fauna was extinct. The blocking of the marine corridors could temporarily reduce genetic exchanges between ancestral populations of Ophiothrix in Europe, which subsequently separated into two Atlantic refuges, one in the colder region (North Sea and north of the British Islands) and the other in warmer southern Europe. This scenario could account for the initial divergence between Lineages I and II. A posterior expansion of the northern lineage towards South Europe with the opening of the North Sea Basin and the English Channel during 
subsequent sea-level increases may explain the present-day picture of secondary contacts between the separate lineages, both overlapping in NW Spain. The refilling of the Mediterranean Sea by Atlantic water via the Strait of Gibraltar, after the salinity crisis, could allow the colonization of the Mediterranean by both lineages already formed. Lineage II could spread all along the rocky littoral of the Mediterranean, whereas the Lineage I, preadapted to colder conditions, remained restricted to deep soft habitats where seawater temperature is lower and more stable. Several marine invertebrates along the Atlantic coast of Europe seem to share a similar history of vicariance on both sides of the English Channel, suggesting the importance of the Mio-Pliocene transition in the speciation processes of Atlantic marine fauna (Jolly et al. 2005, 2006; Muths et al. 2006). Divergence by vicariance events has been invoked as one of the most likely models of genetic differentiation at sea, fuelling speciation processes (Palumbi 1994; Cunningham \& Collins 1998; Lessios et al. 2001; Wares 2001; Waters et al. 2004; Addison \& Hart 2005; Muths et al. 2006). However, the effect of environmental gradients such as bathymetry (Muths et al. 2006) or temperature cannot be completely discarded (Schroth et al. 2002).

Biogeographic boundaries have important implications in terms of evolutionary processes such as mating isolation, maintenance of hybrid zones and speciation (Rios et al. 2002; Jolly et al. 2005; Riginos \& Cunningham 2005), and invertebrates living across such barriers have revealed major phylogeographic divergences (Williams \& Benzie 1998; Waters \& Roy 2003; Peijnenburg et al. 2006; Jolly et al. 2005; Muths et al. 2006; Hunter \& Halanych 2008, 2010 among others). The existence of a current biogeographic break between the colder North Atlantic and the warmer Lusitanian province in the shallow littoral area (Spalding et al. 2007) may not be responsible for the initial genetic divergence of Ophiothrix lineages, but may be the force acting in the maintenance of the two species that differentiated in the past. In the littoral of Galicia, where the yearly average of sea surface temperature is around $16^{\circ} \mathrm{C}$, both species can coexist in the shallow littoral. In southern Atlantic localities, such as Cascais and Algarve in Portugal, where seawater temperature is significantly higher (around $17.6^{\circ} \mathrm{C}$ and $19^{\circ} \mathrm{C}$, respectively), only Lineage II is present in shallow waters.

Baric \& Sturmbauer (1999) speculated that the so-called Lineage II represents the primary colonizers after the refilling of the Mediterranean Sea (about 5 million years ago) and has since evolved to a distinct species. The presence of Lineage I within the Mediterranean Sea, according to these authors, was then a secondary invasion, caused by natural means or ballast water (Carlton 1985; Carlton \&
Geller 1993). Nevertheless, the hypothesis of Baric \& Sturmbauer (1999) was based on a reduced number of samples and localities. For instance, these authors were not aware of the presence of Lineage II along South Atlantic shallow populations. According to their hypothesis, this would require a secondary spillover of Lineage II from the Mediterranean to the Atlantic. Thus, two reciprocal crossings of the Gibraltar divide by the two Lineages should be invoked under the hypothesis of a Mediterranean origin of Lineage II. Although species translocation from their native range to new areas is extremely common and widespread in the marine realm, including brittle stars species (Roy \& Sponer 2002), we favour here the alternative and more parsimonious view of an Atlantic origin of Lineages I and II with a secondary colonization of the Mediterranean by the already-differentiated lineages.

\section{Demographic events and population genetics of Lineage II}

Sequences of the $16 \mathrm{~S}$ and COI from Lineage II provided further insight into the historical demography, population structure and connectivity of the species. The population genetics of this clade of Ophiothrix was characterized by a high genetic diversity and a lack of population differentiation across the geographic range studied.

We have found an apparent panmixia along the AtlantoMediterranean rocky shore. The weak genetic structuring between populations and basins suggests (i) that a lack of barriers to gene flow within the studied area and (ii) that the Gibraltar divide does not prevent interchange between populations on both sides. Although previous reports on the biology of $O$. fragilis should be taken with caution because most studies have been focused on the English Channel and in the North Sea, and so presumably on Lineage I, we may tentatively extrapolate this information to Lineage II. Ophiotbrix fragilis was described as a species with high fecundity and moderately long lifespan of the larvae, estimated at 21-26 days (Lefebvre 1999; Morgan \& Jangoux 2002; data from the English Channel and Netherlands). This could be one of the causes of the lack of genetic structure of the species. Due to their suspension feeding activity, adults of $O$. fragilis are usually found in areas with moderate hydrodynamism (Warner 1971; Davoult 1989; Morgan \& Jangoux 2004); therefore, hydrological regimes and a potentially long period of time in the water column can promote wide dispersal and enhance connectivity and gene flow among distant areas.

Nevertheless, the apparent panmixia detected contrasts with genetic patterns found in other marine invertebrates with similar life history and planktotrophic larvae along the same geographic area (Borsa et al. 1997; Pérez-Losada et al. 2002; Zane et al. 2000; Patarnello et al. 2007), which 
displayed a more or less marked genetic break between the Atlantic and the Mediterranean basins. Notably, genetic breaks within this particular area (Duran et al. 2004; Calderon et al. 2008; Maltagliati et al. 2010; Borrero-Pérez et al. 2011) and patterns of isolation by distance (Zulliger et al. 2009) have been detected in echinoderms with longlived larvae. Thus, other demographic events may be involved in the lack of genetic differentiation detected herein. The characteristic star-shaped genealogy (Slatkin \& Hudson 1991), unimodal mismatch distributions (Rogers \& Harpending 1992) and significant values of the neutrality tests detected are consistent with a recent demographic expansion of the populations. Demographic expansions may homogenize genetic variability along the whole distribution range and increase genetic diversity by the retention of new genetic variants in low frequencies (Avise et al. 1984). The estimation from the COI fragment suggests that demographic expansion happened during the Pleistocene period (250.000 years ago) in Lineage II of Ophiothrix. Demographic expansions have been attributed to episodes of marine-level oscillations during this geological period and are well documented for many marine species in Europe (Maggs et al. 2008). Thus, a combination of present-day and historical processes (high gene flow and the homogenizing effect of a recent expansion in both lineages) may both contribute to the lack of genetic differentiation detected between populations and basins. On the other hand, the extremely high genetic diversity found in Ophiotbrix seems to be a characteristic of some abundant ophiuroids likely related to large population sizes (Muths et al. 2006, 2009; Hunter \& Halanych 2010), which makes populations less sensitive to drift and helps maintain a high level of low-frequency haplotypes (Peijnenburg et al. 2006; Muths et al. 2009). This can explain the unusual pattern displayed by COI, with an almost complete dominance of private haplotypes separated by one or a few mutations. A large effective population size is congruent with the large abundance of the specimens observed in some localities at $2-15 \mathrm{~m}$ depth (author's personal observation).

The results obtained for Lineage II in South Europe were similar to the pattern observed for Lineage I along the English Channel and the British Islands by Muths et al. (2009) but, in that case, the lack of geographic structure was attributed to an admixture of ecotype varieties and/or temporal cohorts. We did not detect the existence of different ecotypes in our samples, and we tried to collect specimens with similar adult size to avoid any cohort effect. However, we detected a clear demographic expansion in Lineage I that may explain the lack of structure found by these authors. It should be noted that in the study by Muths et al. (2009), allozyme analyses did detect a significant differentiation between populations, in clear contrast with mtDNA data, which suggests that re-analysing populations of Lineage II with more variable nuclear markers may reveal additional population differentiation.

In conclusion, two different Ophiothrix species inhabit European waters, and they do not correspond to traditional taxonomic distinctions. Paradoxically, the morphological features of our Lineage I, abundant in the northern Atlantic, correspond more to the morphology of the nominal species O. quinquemaculata from the Mediterranean. Although we cannot rely on the literature, where the two species (and varieties) have repeatedly been confused, it seems that the deep-water form in the Mediterranean described as $O$. quinquemaculata can belong to either of the two genetic lineages detected. As the name $O$. fragilis has historical preference, the use of $O$. quinquemaculata should be abandoned. Given that Lineage I is found in NE Atlantic, where the species was described, the name $O$. fragilis should be applied to this lineage. A new specific name should be erected for Lineage II, but this is better left pending until more detailed morphological analyses can be performed. The maintenance of the so-called $O$. fragilis varieties (again likely a mixture of the two species) seems to make little sense in the light of our results. The phylogeographic history of the two species is not fully resolved, but it was surely linked to phenomena occurring at the end of the Mio-Pliocene, coupled with processes linked to the Pleistocene climatic changes in the zone. For the most abundant lineage in this study (Lineage II), we detected a lack of genetic structure among populations and basins, possibly reflecting a recent expansion, large population sizes and high present-day gene flow. Further studies should aim at analysing deep-water populations in the Mediterranean to ascertain the degree of intermingling of the two lineages in this sea. The study of populations in the Atlantic south of Gibraltar would also be invaluable to complete the picture of the distribution of the two recognized species.

\section{Acknowledgements}

This research was supported by a 'Beatriu de Pinós' contract (Comissionat per a Universitats i Recerca from Departament d'Innovació, Universitats i Empresa, Generalitat de Catalunya) and a 'Juan de la Cierva' contract (Ministry of Science from the Spanish Government) to RPP. Funding was provided by projects CTM201022218 (BENTHOMICS) of the Ministry of Science from the Spanish Government, SGR2009-484 of the Catalan Government, BIO-CONV08-187 of the BBVA Foundation, COCONET project from the EU-FP7 (n. 287844) and the Pluriannual Program (FCT, UI\&D 331/94, partially FEDER funded) from Portugal. Comments by one 
anonymous referee contributed to improve the manuscript. Patrick M. Erwin read the manuscript and provided useful comments and English edition. We thank Owen Wangensteen, Cruz Palacín, Isabel Calderón, Daniel Martín, Fernando Roneberg and Joana Robalo for their help with field collection and/or technical support.

\section{References}

Addison, J. A. \& Hart, M. W. (2005). Colonization, dispersal, and hybridization influence phylogeography of North Atlantic sea urchins (Strongylocentrotus droebachiensis). Evolution, 59, 532-543.

Avise, J. C. (1994). Molecular Markers, Natural History and Evolution. London: Chapman and Hall.

Avise, J. C., Neigel, J. E. \& Arnold, J. (1984). Demographic influences on mitochondrial DNA lineage survivorship in animal populations. Fournal of Molecular Evolution, 20, 99-105.

Bandelt, H. J., Forster, P. \& Rohl, A. (1999). Median-joining networks for inferring intraspecific phylogenies. Molecular Biology and Evolution, 16, 37-48.

Baric, S. \& Sturmbauer, C. (1999). Ecological parallelism and cryptic species in the genus Ophiotbrix derived from mitochondrial DNA sequences. Molecular Phylogenetics and Evolution, 11, 157-162.

Baus, E., Darrock, D. J. \& Bruford, M. W. (2005). Phylogeography of the Antarctic planktotrophic brittle star Ophionotus victoriae reveals genetic structure inconsistent with early life history. Molecular Ecology, 14, 3373-3382.

Benzie, J. A. H. (1999). Major genetic differences between crown of thorns starfish (Acanthaster planci) populations in the Indian and Pacific Oceans. Evolution, 53, 1782-1795.

Bermingham, E. \& Lessios, H. A. (1993). Rate variation of protein and mitochondrial DNA evolution as revealed by sea urchins separated by the Isthmus of Panama. Proceedings of the National Academy of Sciences, USA, 90, 2734-2738.

Bickford, D., Lohman, D. J., Sodhi, N. S., Ng, P. K. L., Meier, R., Winker, K., Ingram, K. K. \& Das, I. (2007). Cryptic species as a window on diversity and conservation. Trends in Ecology \& Evolution, 22, 148-155.

Boissin, E., Feral, J. P. \& Chenuil, A. (2008). Defining reproductively isolated units in a cryptic and syntopic species complex using mitochondrial and nuclear markers: the brooding brittle star, Amphipholis squamata (Ophiuroidea). Molecular Ecology, 17, 1732-1744.

Boissin, E., Stöhr, S. \& Chenuil, A. (2011). Did vicariance and adaptation drive cryptic speciation and evolution of brooding in Ophioderma longicauda (Echinodermata: Ophiuroidea), a common Atlanto-Mediterranean ophiuroid. Molecular Ecology, 2, 4737-4755.

Borrero-Pérez, G. H., González-Wangüemert, M. C. \& PérezRuzafa, A. (2011). Phylogeography of the AtlantoMediterranean sea cucumber Holothuria (Holothuria) mammata: the combined effects of historical processes and current oceanographical pattern. Molecular Ecology, 20, 1964-1975.

Borsa, P., Naciri, M., Bahri, L., Chikhi, L., Garcia de León, F. J., Kotoulas, G. \& Bonhomme, F. (1997). Intraspecific zoogeography of the Mediterranean: population genetic analysis on sixteen Atlanto-Mediterranean species (fishes and invertebrates). Vie et Milieu, 47, 295-305.
Brault, N., Bourquin, S., Guillocheau, F., Dabard, M. P., Bonnet, S., Courville, P., Estéoule-Choux, J. \& Stepanoff, F. (2004). Mio-Pliocene to Pleistocene paleotopographic evolution of Britanny (France) from a sequence stratigraphic analysis: relative influence of tectonics and climate. Sedimentary Geology, 163, 175-210.

Broom, D. M. (1975). Aggregation behaviour of the brittlestar Ophiothrix fragilis. Fournal of the Marine Biological Association of UK, 55, 191-197.

Bucklin, A., Steinke, D. \& Blanco-Bercial, L. (2011). DNA Barcoding of marine metazoa. Annual Review of Marine Science, 3, 471-508.

Calderon, I., Giribet, G. \& Turon, X. (2008). Two markers and one history: phylogeography of the edible common sea urchin Paracentrotus lividus in the Lusitanian region. Marine Biology, $154,137-151$.

Carlton, J. T. (1985). Transoceanic and interoceanic dispersal of coastal marine organisms: the biology of ballast water. Oceanography and Marine Biology: An Annual Review, 23, 313-371.

Carlton, J. T. \& Geller, B. (1993). Ecological roulette: the global transport of nonindigenous marine organisms. Science, 261, 78-82.

Chevolot, M., Hoarau, G., Rijnsdorp, A. D. \& Stam, W. T. (2006). Phylogeography and population structure of thornback rays (Raja clavata L., Rajidae). Molecular Ecology, 15, 3693-3705.

Cimmaruta, R., Bondanelli, P. \& Nascetti, G. (2005). Genetic structure and environmental heterogeneity in the European hake (Merluccius merluccius). Molecular Ecology, 14, 2577-2591.

Cox, B. C. \& Moore, P. D. (2000). Biogeography: An Ecological and Evolutionary Approach. London: Blackwell Scientific Publications.

Cunningham, C. W. \& Collins, T. M. (1998). Beyond area relationships: extinction and recolonization in molecular marine biogeography. In B. Schierwater, B. Streit, G. Wagner \& R. DeSalle ((Eds)) Molecular Ecology and Evolution: Approaches and Applications (pp. 297-321). Basel: Birkhauser Verlag.

Davoult, D. (1989). Structure démografique et production de la population d'Ophiothrix fragilis (Abildgaard) du Détroit du Pasde-Calais, France. Vie Marine, 10, 116-127.

Davoult, D. \& Gounin, F. (1995). Suspension-feeding activity of a dense Ophiothrix fragilis (Abildgaard) population at the watersediment interface: time coupling of food availability and feeding behaviour of the species. Estuarine and Coastal Shelf Science, 41, 567-577.

Davoult, D., Gounin, F. \& Richard, A. (1990). Dynamique et reproduction de la population d'Ophiothrix fragilis (Abildgaard) du détroit du Pas de Calais (Manche Orientale). Fournal of Experimental Marine Biology and Ecology, 138, 201-216.

Duggen, K., Hoernle, P. V. D., Boogard, L. \& Morgan, J. P. (2003). Deep roots of the Messinian salinity crisis. Nature, 422, 602-606.

Duran, S., Palacin, C., Becerro, M. A., Turon, X. \& Giribet, G. (2004). Genetic diversity and population structure of the commercially harvested sea urchin Paracentrotus lividus (Echinodermata, Echinoidea). Molecular Ecology, 13, 3317-3328.

Excoffier, L., Laval, G. \& Schneider, S. (2005). Arlequin (version 3.0): an integrated software package for population genetics data analysis. Evolutionary Bioinformatics Online, 1, 47-50.

Fedra, K., Ölscher, E. M., Scherübel, C., Stachowitsch, M. \& Wurzian, R. S. (1976). On the ecology of the North Adriatic 
benthic community: distribution, standing crop and composition of the macrobenthos. Marine Biology, 38, 129-145.

Feral, J. P. (2002). How useful are the genetic markers in attempts to understand and manage marine biodiversity? Fournal of Experimental Marine Biology and Ecology, 268, 121145.

Folmer, O., Black, M., Hoeh, W., Lutz, R. \& Vrijenhoek, R. (1994). DNA primers for amplification of mitochondrial cytochrome $\mathrm{c}$ oxidase subunit I from diverse metazoan invertebrates. Molecular Marine Biology and Biotechnology, 3, 294299.

Fu, Y. X. (1997). Statistical test of neutrality of mutations against population growth, hitchhiking and background selection. Genetics, 147, 915-925.

Guille, A. (1964). Contribution à l'étude de la systématique et de l'écologie d'Ophiothrix quiquemaculata Delle Chiaje. Vie Milieu, 15, 243-308.

Hall, T. A. (1999). BioEdit: a user-friendly biological sequence alignment editor and analysis program for Windows 95/98/NT. Nucleic Acids Symposium Series, 41, 95-98.

Hart, M. W. \& Podolsky, R. D. (2005). Mitochondrial DNA phylogeny and rates of larval evolution in Macrophiothrix brittlestars. Molecular Phylogenetics and Evolution, 34, 438-447.

Hart, M. W., Byrne, M. \& Smith, M. J. (1997). Molecular phylogenetic analysis of life-history evolution in Asterinid starfish. Evolution, 51, 1848-1861.

Hebert, P. D. N., Ratnasingham, S. \& de Waard, J. R. (2003). Barcoding animal life: cytochrome $\mathrm{c}$ oxidase subunit I divergences among closely related species. Proceedings of the Royal Society of London, 270, 96-99.

Hoareau, T. B. \& Boissin, E. (2010). Design of phylum-specific hybrid primers for DNA barcoding: addressing the need for efficient COI amplification in the Echinodermata. Molecular Ecology Resources, 10, 960-967.

Hunter, R. L. \& Halanych, K. M. (2008). Evaluating connectivity in the brooding brittle star Astrotoma agassizii across the Drake passage in the Southern Ocean. Fournal of Heredity, 99, 137-148.

Hunter, R. L. \& Halanych, K. M. (2010). Phylogeography of the Antarctic planktotrophic brittle star Ophionotus victoriae reveals genetic structure inconsistent with early life history. Molecular Ecology, 157, 1693-1704.

Jolly, M. T., Jollivet, D., Gentil, F., Thiébaut, E. \& Viard, F. (2005). Sharp genetic break between Atlantic and English Channel populations of the polychaete Pectinaria koreni, along the north coast of Britanny, France. Heredity, 94, 23-32.

Jolly, M. T., Viard, F., Gentil, F., Thiebaut, E. \& Jollivet, D. (2006). Comparative phylogeography of two coastal polychaete tubeworms in the Northeast Atlantic supports shared history and vicariant events. Molecular Ecology, 15, 1841-1855.

Jombart, T., Devillard, S., Dufour, A. B. \& Pontier, D. (2008). Revealing cryptic spatial patterns in genetic variability by a new multivariate method. Heredity, 101, 92-103.

Jombart, T., Devillard, S. \& Balloux, F. (2010). Discriminant analysis of principal components: a new method for the analysis of genetically structured populations. BMC Genetics, 11, 94.

Jost, L. (2008). G $\mathrm{G}_{\mathrm{ST}}$ and its relatives do not measure differentiation. Molecular Ecology, 17, 4015-4026.

Kirby, R. R. \& Lindley, J. A. (2005). Molecular analysis of Continuous Plankton Recorder samples, an examination of echinoderm larvae in the North Sea. Fournal of the Marine Biological Association of the U.K., 85, 451-459.

Knowlton, N. (1993). Sibling species in the sea. Annual Review of Ecology, Evolution and Systematics, 24, 189-216.

Knowlton, N. (2000). Molecular genetic analyses of species boundaries in the sea. Hydrobiologia, 420, 73-90.

Koehler, R. (1921). Faune de France. 1 Echinodermes. Paris: Lechevalier.

Launey, S., Ledu, C., Boudry, P., Bonhomme, F. \& NaciriGraven, Y. (2002). Geographic structure in the European flat oyster (Ostrea edulis L.) as revealed by microsatellite polymorphism. Fournal of Heredity, 93, 331-338.

Le Gac, M., Feral, J. P., Poulin, E., Veyret, M. \& Chenuil, A. (2004). Identification of allopatric clades in the cosmopolitan ophiuroid species complex Amphipholis squamata (Echinodermata). The end of a paradox?. Marine Ecology Progress Series, 278, 171-178.

Lee, C. E. (2000). Global phylogeography of a cryptic copepod species complex and reproductive isolation between genetically proximate "populations". Evolution, 54, 2014-2027.

Lee, M. (2004). The molecularisation of taxonomy. Invertebrate Systematics, 18, 1-6.

Lefebvre, A. (1999). Reproduction d'une espèce benthique à phase larvaire planctonique, l'ophiure Ophiothrix fragilis (Echinoderme), dans un système côtier à fort hydrodynamisme (détroit du Pas-de-Calais): interactions physique-biologie et implications dans le fonctionnement global de l'écosystème. $\mathrm{PhD}$ dissertation, University of Lille 1, Lille.

Lessios, H. A., Kessing, B. D., Robertson, D. R. \& Paulay, G. (1999). Phylogeography of the pantropical sea urchin Eucidaris in relation to land barriers and ocean currents. Evolution, 53, 806-817.

Lessios, H. A., Kessing, B. D. \& Pearse, J. S. (2001). Population structure and speciation in tropical seas: global phylogeography of the sea urchin Diadema. Evolution, 55, 955-975.

Librado, P. \& Rozas, J. (2009). naSP v5: a software for comprehensive analysis of polymorphism data. Bioinformatics, $25,1451-1452$.

Maggs, C. A., Castilho, R., Foltz, D., Henzler, C., Jolly, M. T., Kelly, J., Olsen, J., Perez, K. E., Stam, W., Vainola, R., Viard, F. \& Wares, J. (2008). Evaluating signatures of the glacial refugia for North Atlantic benthic marine taxa. Ecology, 89, 108-122.

Maldonado, A. (1985). Evolution of the Mediterranean basins and a detailed reconstruction of the Cenozoic paleoceanography. In R. Margalef (Ed) Key Environments: Western Mediterranean (pp. 17-59). Oxford: Pergamon Press.

Maltagliati, F., Giuseppe, G. D., Barbieri, M., Castelli, A. \& Dini, F. (2010). Phylogeography and genetic structure of the edible sea urchin Paracentrotus lividus (Echinodermata: Echinoidea) inferred from the mitochondrial cytochrome $b$ gene. Biological Fournal of the Linnean Society, 100, 910-923.

Meulenkamp, J. E. \& Sissingh, W. (2003). Tertiary palaeogeography and tectonostratigraphic evolution of the Northern and Southern Peri-Tethys platforms and the intermediate domains of the African-Eurasian convergent plate boundary zone. Palaeogeography, Palaeoclimatology, Palaeoecology, 196, 209-228.

Monteiro, F. A., Sole-Cava, A. M. \& Thorpe, J. P. (1997). Extensive genetic divergence between populations of the 
common intertidal sea anemone Actinia equina from Britain, the Mediterranean and the Cape Verde Islands. Marine Biology, 129, 425-433.

Morgan, R. \& Jangoux, M. (2002). Reproductive cycle and spawning induction in the gregarious brittle star Ophiotbrix fragilis (Echinodermata) in the Oosterschelde (Netherlands). Invertebrate Reproduction and Development, 142, 145-155.

Morgan, R. \& Jangoux, M. (2004). Assessing arm regeneration and its effect during the reproductive cycle in the gregarious brittle-star Ophiothrix fragilis (Echinodermata). Cabiers de Biologie Marine, 45, 277-280.

Muths, D., Davoult, D., Gentil, F. \& Jollivet, D. (2006). Incomplete cryptic speciation between intertidal and subtidal morphs of Acrocnida brachiata (Echinodermata: Ophiuroidea) in the Northeast Atlantic. Molecular Ecology, 15, 3303-3318.

Muths, D., Jollivet, D., Gentil, F. \& Davoult, D. (2009). Largescale genetic patchiness among NE Atlantic populations of the brittle star Ophiothrix fragilis. Aquatic Biology, 5, 117-132.

Narum, S. R. (2006). Beyond Bonferroni: less conservative analyses for conservation genetics. Conservation Genetics, 7, 783787.

Palero, F., Abelló, P., Macpherson, E., Gristina, M. \& Pascual, M. (2008). Phylogeography of the European spiny lobster (Palinurus elephas): influence of current oceanographical features and historical processes. Molecular Phylogenetics and Evolution, 48, 708-717.

Palumbi, S. R. (1994). Genetic divergence, reproductive isolation, and marine speciation. Annual Review of Ecology, Evolution and Systematics, 25, 547-572.

Palumbi, S. R. (1995). Using genetics as an indirect estimator of larval dispersal. In M. L (Ed) Ecology of Marine Invertebrate Larvae (pp. 369-387). Boca Raton, FL: CRC Press.

Patarnello, T., Volckaert, F. \& Castilho, R. (2007). Pillars of Hercules: is the Atlantic-Mediterranean transition a phylogeographical break?. Molecular Ecology, 16, 4426-4444.

Peijnenburg, K., Fauvelot, C., Breeuwer, A. J. \& Menker, S. B. (2006). patial and temporal genetic structure of the planktonic Sagitta setosa(Chaetognatha) in European seas as revealed by mitochondrial and nuclear DNA markers. Molecular Ecology, 15, 3319-3338.

Pérez-Losada, M., Guerra, A., Carvalho, G. R., Sanjuan, A. \& Shaw, P. W. (2002). Extensive population subdivision of the cuttlefish Sepia officinalis (Mollusca: Cephalopoda) around the Iberian Peninsula indicated by microsatellite DNA variation. Heredity, 89, 417-424.

Pérez-Losada, M., Nolte, M. J., Crandall, K. A. \& Shawn, P. W. (2007). Testing hypotheses of population structuring in the Northeast Atlantic ocean and Mediterranean sea using the common cuttlefish Sepia officinalis. Molecular Ecology, 16, 26672679.

Pérez-Portela, R. \& Turon, X. (2008). Cryptic divergence and strong population structure in the colonial invertebrate Pycnoclavella communis (Ascidiacea) inferred from molecular data. Zoology, 111, 163-178.

Pérez-Portela, R., Villamor, A. \& Almada, V. (2010). Phylogeography of the sea star Marthasterias glacialis (Asteroidea, Echinodermata): deep genetic divergence between mitochondrial lineages in the Mediterranean. Marine Biology, 157, 2015-2028.
Petit, R. J., El Mousadik, A. \& Pons, O. (1998). Identifying populations for conservation on the basis of genetic markers. Conservation Biology, 12, 844-855.

Ramos-Onsins, S. E. \& Rozas, J. (2002). Statistical properties of new neutrality tests against population growth. Molecular Biology and Evolution, 19, 2092-2100.

Riginos, C. \& Cunningham, C. V. (2005). Local adaptation and species segregation in two mussel (Mytilus edulis $x$ Mytilus trossulus) hybrid zones. Molecular Ecology, 14, 381-400.

Rios, C., Sanz, S., Saavedra, C. \& Pena, J. B. (2002). Allozyme variation in populations of scallops, Pecten jacobaeus (L.) and $P$ maximus (L.) (Bivalvia : Pectinidae), across the Almeria-Oran front. Fournal of Experimental Marine Biology and Ecology, 267, 223-244.

Rogers, A. R. (1995). Genetic-evidence for a pleistocene population explosion. Evolution, 49, 608-615.

Rogers, A. R. \& Harpending, H. (1992). Population-growth makes waves in the distribution of pairwise genetic-differences. Molecular Biology and Evolution, 9, 552-569.

Roy, M. S. \& Sponer, R. (2002). Evidence of a human-mediated invasion of the tropical western Atlantic by the 'world's most common brittlestar. Proceedings of the Royal Society of London Series B-Biological Sciences, 269, 1017-1023.

Schroth, W., Jarms, G., Streit, B. \& Schierwater, B. (2002). Speciation and phylogeography in the cosmopolitan marine moon jelly, Aurelia sp. BMC Evolutionary Biology, 2, 1-10.

Slatkin, M. \& Hudson, R. R. . (1991). Pairwise comparisons of mitochondrial DNA sequences in stable and exponentially growing populations. Genetics, 129, 555-562.

Spalding, M. D., Fox, H. E., Allen, G. R., Davidson, N., Ferdaña, Z. A., Finlayson, M., Halpern, B. S., Miguel, A. J., Lombana, A. L., Lourie, S. A., Martin, K. D., McManus, E., Molnar, J., Recchia, C. A. \& Robertson, J. (2007). Marine ecoregions of the world: a bioregionalization of coastal and shelf areas. BioScience, 57, 573-583.

Sponer, R., Deheyn, D. \& Roy, M. S. (2001). Large genetic distances within a population of Amphipholis squamata (Echinodermata; Ophiuroidea) do not support colour varieties as sibling species. Marine Ecology Progress Series, 219, 169-175.

Templeton, A. R. \& Sing, C. F. (1993). A cladistic-analysis of phenotypic associations with haplotypes inferred from restriction endonuclease mapping 4. Nested analyses with cladogram uncertainty and recombination. Genetics, 134, 659-669.

Templeton, A. R., Boerwinkle, E. \& Sing, C. F. (1987). A cladistic analysis of phenotypic associations with haplotypes inferred from restriction endonuclease mapping. I. Basic theory and an analysis of alcohol dehydrogenase activity in Drosophila. Genetics, 117, 343-351.

Tintoré, J., Laviolette, P. E., Blade, I. \& Cruzado, A. (1988). A study of an intense density front in the Eastern Alboran-Seathe Almeria-Oran Front. Fournal of Physical Oceanography, 18, 1384-1397.

Tortonese, E. (1965). Echinodermata. Fauna d'Italia. Bologna: Calderini.

Turon, X., Codina, M., Tarjuelo, I., Uriz, M. J. \& Becerro, M. A. (2000). Mass recruitment of Ophiothrix fragilis(Ophiuroidea) on sponges: settlement patterns and post-settlement dynamics. Marine Ecology Progress Series, 200, 201-212. 
Uthicke, S. \& Benzie, J. A. H. (2003). Gene flow and population history in high dispersal marine invertebrates: mitochondrial DNA analysis of Holothuria nobilis (Echinodermata: Holothuroidea) populations from the Indo-Pacific. Molecular Ecology, 12, 2635-2648.

Uthicke, S., Byrne, M. \& Conand, C. (2010). Genetic barcoding of commercial Bêche-de-mer species (Echinodermata: Holothuroidea). Molecular Ecology Resources, 10, 634-646.

Ward, R. D., Holmes, B. H. \& O'Hara, T. D. (2008). DNA barcoding discriminates echinoderm species. Molecular Ecology Resources, 8, 1202-1211.

Wares, J. P. (2001). Biogeography of Asterias: North Atlantic climate change and speciation. Biological Bulletin, 201, 95-103.

Wares, J. P. \& Cunningham, C. W. (2001). Phylogeography and historical ecology of the North Atlantic intertidal. Evolution, 55, 2455-2469.

Warner, G. F. (1971). On the ecology of a dense bed of the brittle-star Ophiothrix fragilis. Fournal of the Marine Biological Association of UK, 51, 267-282.

Warner, G. F. \& Woodley, J. D. (1975). Suspension-feeding in the brittle-star Ophiothrix fragilis. Fournal of the Marine Biological Association of UK, 55, 199-210.

Waters, J. M. \& Roy, M. S. (2003). Marine biogeography of southern Australia: phylogeographical structure in a temperate sea-star. Fournal of Biogeography, 30, 1787-1796.

Waters, J. M., O'Loughlin, P. M. \& Roy, M. S. (2004). Cladogenesis in a starfish species complex from southern Australia: evidence for vicariant speciation?. Molecular Phylogenetics and Evolution, 32, 236-245.

Williams, S. T. \& Benzie, J. A. H. (1998). Evidence of a biogeographic break between populations of a high dispersal starfish: congruent regions within the Indo-West Pacific defined by colour morphs, mtDNA and allozyme data. Evolution, 52, 87-99.

Zane, L., Ostellari, L., Maccatrozzo, L., Bargellon, I. L., CuzinRoudy, J., Buchholz, F. \& Patarnello, T. (2000). Genetic differentiation in a pelagic crustacean (Meganyctiphanes norvegica: Euphausiacea) from the North East Atlantic and the Mediterranean Sea. Marine Biology, 136, 191-199.

Zavodnik, D. (1976). Adriatic echinoderms inhabiting benthic organisms. Thalassia fugoslavica, 12, 375-380.

Zulliger, D., Tanner, S., Ruch, M. \& Ribi, G. (2009). Genetic structure of the high dispersal Atlanto-Mediterranean sea star Astropecten aranciacus revealed by mitochondrial DNA sequences and microsatellite loci. Marine Biology, 156, 597-610.

\section{Supporting information}

Additional Supporting Information may be found in the online version of this article:

Fig. S1. Mismatch distribution. Graphs represent the mismatch distribution for the $16 \mathrm{~S}$ and COI fragments, for both lineages of Ophiothrix.

Fig. S2. Scatterplot of the multivariate analysis DAPC for populations of Ophiothrix from Lineage II. It shows the first two principal components of the DAPC and summarizes genetic differentiation between groups. Populations (groups) are presented by different colours and inertia ellipses, while dots represent individuals from every population. ROS: Roscoff; FER: Ferrol; CAS: Cascais; APA: Armaçao de Pera; CEU: Ceuta; LH: La Herradura; XAB: Xábia; BLA: Blanes; RS: Roses; CAD: Cadaqués; AL: Alcudia; LK: Ladiko; and KB: Kalytea Bay.

Table S1. List of the haplotypes sequenced in this study. Haplotype name, accession number from Genbank (pending), number of individuals belonging to each haplotype per population, and total number of individuals for the $16 \mathrm{~S}$ and COI genes.

Table S2. Genetic divergence between species of the genus Ophiothrix for the COI gene. Accession numbers for sequences obtained from Genbank are included in brackets.

Table S3. Neutrality tests and Raggedness statistics ( $r)$.

* Significant at $P<0.05$ and ** highly significant at $P<0.01$.

Table S4. AMOVA grouping populations of Ophiothrix (Lineage II) within Mediterranean and Atlantic basins for both genes, 16S and COI, separately.

Please note: Wiley-Blackwell are not responsible for the content or functionality of any supporting materials supplied by the authors. Any queries (other than missing material) should be directed to the corresponding author for the article. 